\title{
A generic framework to assess the representation and protection of benthic ecosystems in European marine protected areas
}

\author{
Clare Greathead $^{1}$ ( ) | Paolo Magni ${ }^{2}$ ( ) | Jan Vanaverbeke ${ }^{3}$ | \\ Lene Buhl-Mortensen ${ }^{4}$ () | Urszula Janas ${ }^{5}$ | Mats Blomqvist ${ }^{6}$ (i) | \\ Johan A. Craeymeersch ${ }^{7}$ (1) | Jennifer Dannheim ${ }^{8,9}$ @ | Alexander Darr ${ }^{10}$ | \\ Steven Degraer ${ }^{3}$ | Nicolas Desroy ${ }^{11}$ ( ) Annick Donnay ${ }^{12}$ | Yessica Griffiths ${ }^{13}$ | \\ Ivan Guala ${ }^{14}$ ( ) | Laurent Guerin ${ }^{15}$ | Hayley Hinchen ${ }^{13}$ | Celine Labrune ${ }^{16}$ (1) | \\ Henning Reiss ${ }^{17}$ | Gert Van Hoey ${ }^{18}$ | Silvana N.R. Birchenough ${ }^{19}$ \\ ${ }^{1}$ Marine Scotland Science, Planning and Environmental Advice, Ecology and Conservation Group, Aberdeen, UK \\ ${ }^{2}$ National Research Council of Italy, Institute of Anthropic Impact and Sustainability in Marine Environment (CNR-IAS), Torregrande-Oristano, Italy \\ ${ }^{3}$ Royal Belgian Institute of Natural Sciences, Operational Directorate Natural Environment, Marine Ecology and Management, Brussels, Belgium \\ ${ }^{4}$ Institute of Marine Research, Bergen, Norway \\ ${ }^{5}$ Institute of Oceanography, University of Gdansk, Gdynia, Poland \\ ${ }^{6}$ Hafok AB, Stenhamra, Sweden \\ ${ }^{7}$ Wageningen Marine Research, Wageningen University, Yerseke, the Netherlands \\ ${ }^{8}$ Alfred Wegener Institute, Helmholtz Centre for Polar and Marine Research, Bremerhaven, Germany \\ ${ }^{9}$ Helmholtz Institute for Functional Marine Biodiversity, Oldenburg, Germany \\ ${ }^{10}$ Leibniz Institute for Baltic Sea Research, Department of Biological Oceanography, Rostock, Germany \\ ${ }^{11}$ Ifremer, Laboratoire Environnement et Ressource Bretagne nord, Dinard, France \\ ${ }^{12}$ Station de Recherches Sous-Marines et Océanographiques, Calvi, France \\ ${ }^{13}$ Joint Nature Conservation Committee, Marine Monitoring and Evidence Team, Peterborough, UK \\ ${ }^{14}$ Foundation International Marine Centre (IMC), Torregrande-Oristano, Italy \\ ${ }^{15}$ Office Français de la Biodiversité, Patrimoine Naturel joint unit, Dinard, France \\ ${ }^{16}$ Sorbonne Université, CNRS, Laboratoire d'Ecogéochimie des Environnements, Benthiques, LECOB, 66650, Banyuls-sur-Mer, France \\ ${ }^{17}$ Nord University, Faculty of Biosciences and Aquaculture, Ecology Division, Bodø, Norway \\ ${ }^{18}$ The Flanders Research Institute for Agriculture, Fisheries and Food, Animal Science Department, Oostende, Belgium \\ ${ }^{19}$ The Centre for Environment, Fisheries and Aquaculture Science, Lowestoft, UK
}

Correspondence

Paolo Magni, National Research Council of Italy, Institute of Anthropic Impact and Sustainability in Marine Environment (CNR-IAS), Loc. Sa Mardini Torregrande, 09170 Oristano, Italy.

Email: paolo.magni@cnr.it

\section{Abstract}

1 There is concern across the International Council for the Exploration of the Sea (ICES) region that a consideration of vulnerable components and the wider support mechanisms underpinning benthic marine ecosystems may be lacking from the process of marine protected area (MPA) designation, management and monitoring. 
2 In this study, MPAs across six European ecoregions were assessed from a benthic ecology perspective. The study included 102 MPAs, designated by 10 countries, and focused on three aspects regarding the role of the benthos in: (i) the designation of MPAs; (ii) the management measures used in MPAs; and (iii) the monitoring and assessment of MPAs.

3 Qualitative entries to a questionnaire based on an existing framework (EU project 'Monitoring Evaluation of Spatially Managed Areas', (MESMA) were collected by 19 benthic experts of the ICES Benthic Ecology Working Group. A pedigree matrix was used to apply a numerical scale (score) to these entries.

4 The results showed clear differences in scores between ecoregions and between criteria. The designation-phase criteria generally achieved higher scores than the implementation-phase criteria. Poor designation-phase scores were generally reiterated in the implementation-phase scores, such as scores for assessment and monitoring.

5 Over 70\% of the MPA case studies were found to consider the benthos to some extent during selection and designation; however, this was not followed up with appropriate management measures and good practice during the implementation phase.

6 Poor spatial and temporal coverage of monitoring and ineffective indicators is unlikely to pick up changes caused by management measures in the MPA. There is concern that without adequate monitoring and adaptive management frameworks, the MPAs will be compromised. Also, there could be an increased likelihood that, with regard to the benthos, they will fail to meet their conservation objectives.

7 This assessment was successful in highlighting issues related to the representation and protection of the benthos in MPAs and where changes need to be made, such as expanding the characterization and monitoring of benthic species or habitats of interest. These issues could be attributable to an ongoing process and/or an indication that some MPAs only have 'paper protection'.

\section{KEYWORDS}

benthos, coastal, conservation evaluation, marine protected area, monitoring, ocean

\section{1 | INTRODUCTION}

The designation and management of marine protected areas (MPAs) is an important tool in the protection of the marine environment from anthropogenic pressures (Klein et al., 2015). The current Aichi Biodiversity Target 11 of the Convention on Biological Diversity (CBD) calls for $10 \%$ of coastal and marine areas to be conserved through MPAs or other effective area-based conservation mechanisms by 2020 (CBD, 2010). Current policy recommendations are to fully protect at least $30 \%$ of marine habitats to maximize the benefits of MPAs, however (O'Leary et al., 2016). Also, regional sea conventions (e.g. the Convention for the Protection of the Marine Environment of the North-East Atlantic, OSPAR; Helsinki Convention on the Protection of the Marine Environment of the Baltic Sea Area, HELCOM; and the Barcelona Convention) require member states to provide a coherent and representative network of MPAs that adequately cover the diversity of the constituent ecosystems (Ardron, 2008). Despite these recommendations, only $5.3 \%$ of the world's ocean is protected in implemented and actively managed MPAs today (MPAtlas, 2020).

In Europe, progress in the designation of MPAs has been driven by many different legislative and regulatory processes since the inception of the CBD in 1992 (CBD, 1992), from EU directives such as the Habitats Directive (EEC, 1992) to fisheries management areas under the EU Common Fisheries Policy (CFP, EU 2371/2002) (Horta-e-Costa et al., 2016). Other regional initiatives such as the OSPAR recommendation 2003/3 (OSPAR, 2003), the HELCOM recommendation 15/5 (HELCOM, 1994), the Barcelona Convention (1995), and the Marine Strategy Framework Directive (MSFD, 2008) have played important roles in the delivery of MPAs. 
Marine protected areas (MPAs) are areas that have been reserved by law, or other effective means, to protect part or all of the enclosed environment and associated flora and fauna (International Union for Conservation of Nature, IUCN, 2012). The MPAs should, if designed and managed correctly, contribute to ecological resilience to various pressures caused by anthropogenic activities, such as fishing, pollution and climate change (Roberts et al., 2017). There is concern among benthic ecologists that important aspects that underpin the successful protection of marine benthic ecosystems have not been adequately considered in the process of selecting, managing and monitoring MPAs, despite the important role of marine benthic ecosystems in overall ecosystem functioning. For example, gap analysis showed that for some major invertebrate phyla (Porifera, Cnidaria, Mollusca, Arthropoda and Echinodermata), less than $10 \%$ of the potential habitat of these species was protected within MPAs (Klein et al., 2015). Although this mismatch could sometimes relate to a sparsity of data on the distribution of species and habitats of conservation concern, the selection process for MPAs can sometimes be based on nonecological factors. For example, these might concentrate on protecting areas defined, a priori, by criteria that are mainly linked to local socio-economic needs (Ruiz-Frau et al., 2015), established in remote areas with limited human activities (Jessen et al., 2017), to protect large areas for mobile marine mammals or to secure the stock of commercially harvested species (Lutchman, Brown, \& Kettunen, 2008). As well as the location and the ecosystem components of the MPA, consideration of the adequate size is also important during MPA delineation (Edgar et al., 2014), particularly when creating zones within an MPA with different degrees of protection (Claudet et al., 2008).

Marine benthic ecosystems provide important ecological services, such as food provision (i.e. fisheries) and biodiversity maintenance (Galparsoro, Borja, \& Uyarra, 2014). They are particularly important in the cycling and sequestration of carbon and the regeneration of nutrients (Beaumont et al., 2007; Birchenough, Parker, McManus, \& Barry, 2012; Kent, Gray, Last, \& Sanderson, 2016; Snelgrove et al., 2018), secondary production (Renaud, Morata, Ambrose, Bowie, \& Chiuchiolo, 2007), and the mediation of organic enrichment (Beaumont et al., 2007; Snelgrove et al., 2018). Also, benthic marine species offer a rich source of structurally novel and biologically active metabolites for medicinal use (Abou-Elela, Abd-Elnaby, Ibrahim, \& Okbah, 2009; Shakeel et al., 2018). Furthermore, marine benthic species and habitats provide a wide range of recreational ecosystem services that can be measured either by specific economic benefits (Reynolds \& Braithwaite, 2010), such as the ecotourism activities of diving, rock-pool safaris, and recreational fishing (Barbier et al., 2011; Beukema, 1995; Olive, 1993), or by other health, well-being, and amenity benefits (Gascon, Zijlema, Vert, White, \& Nieuwenhuijsen, 2017; Hooyberg et al., 2020; UNEP, 2006; Wilson, Costanza, Boumans, \& Liu, 2005).

Marine benthic ecosystems, species, and habitats (hereafter referred to as the benthos) are closely associated with the seabed and exhibit either direct reproduction (non-dispersing) or are reliant on currents and tidal flows for propagule dispersal. This close association with the seabed makes the benthos particularly vulnerable to localized pressures on the seabed (Coppa et al., 2016; Van Hoey et al., 2010). Therefore, after designation, programmes of measures need to be applied within MPAs that balance the requirement to achieve conservation objectives with human activity. This should ensure that the structure and functions of the ecosystems are safeguarded, and that benthic ecosystems, in particular, are not adversely affected, as defined under the EU Marine Strategy Framework Directive (MSFD; cf. Descriptor 6: 'Seafloor integrity'). The ecological effectiveness of different management actions varies depending on the species or ecosystem (Dichmont et al., 2013; Mills, Jupiter, Pressey, Ban, \& Comley, 2011). This is because species-specific traits, such as lifecycle attributes, recruitment, migration, trophic interactions, and species interactions, affect how benthic species or habitats respond to different anthropogenic pressures (Farina, Quattrocchi, Guala, \& Cucco, 2018; Frid, Paramor, Brockington, \& Bremner, 2008). Therefore, to successfully protect the benthos, these 'ecological attributes' should be considered in management actions and will require different approaches to fulfil protection and conservation objectives (Shanks, 2009). Gill et al. (2017) suggested that ecological factors are key to enhancing the performance of MPAs, but effective management measures that reduce the negative effects of anthropogenic activities on the benthos are also essential.

Once an MPA has been designated and management measures have been applied, the next important step is to ensure that any changes in the state of the benthos are monitored and assessed. Effective monitoring and assessment programmes for MPAs require accurate baseline data, which first includes a characterization of the habitat, identifying key species of interest and major ecological relationships, and determines the ecological scale of the patterns or processes of interest (at a fine scale, broad scale, or both) (Buhl-Mortensen et al., 2017; Loh, Archer, \& Dunham, 2019). Also, these baseline data should inform the long-term design of the monitoring and assessment programme for the MPA and should highlight any knowledge gaps. These programmes should: be aligned with the conservation and operational objectives of the MPA; use appropriate indicators; be sensitive to identified stressors or management actions; and be integrated into the wider scale of regional monitoring programmes (Buhl-Mortensen et al., 2017; Loh et al., 2019; Van Hoey et al., 2019).

As the Aichi Target 11 (CBD, 2010) deadline approaches, there have been several attempts to develop tools to evaluate the effectiveness of MPAs (Agnesi et al., 2017; Hatton-Ellis et al., 2012; Horta-e-Costa et al., 2016; OSPAR, 2007, 2008; Pomeroy, Parks, \& Watson, 2004; Stelzenmüller et al., 2013; Stolton \& Dudley, 2016). These initiatives, however, did not differentiate between the various biological components under the protection of the MPA, especially the benthic components. Furthermore, although area targets on the whole are likely to be met by 2020 , many MPAs are generally not considered to be representative, adequate, or well managed (Amengual \& Alvarez-Berastegui, 2018; Jessen et al., 2017; Solandt, 2018). Consequently, scientific questions remain with regards to the evaluation and effectiveness of MPAs operating around the 
world, especially with regard to the benthos. This article addresses the concerns outlined above, with specific consideration to the benthos. We assessed a sample of MPAs from a range of countries and European ecoregions, using a generic framework, based on a combination of evidence and the objective opinion of 19 benthic experts (members of the International Council for the Exploration of the Sea Benthic Ecology Working Group, ICES BEWG).

The aims of this study are listed below.

1 To determine whether the benthos played an explicit role in the designation of the MPA.

2 To assess whether management measures were in place that directly target the benthos.

3 Establish whether there were monitoring programmes in place that used appropriate indicators and tools to assess the effectiveness of any management measures for the benthos, based on the definitions used by Stelzenmüller et al. (2013) and Stelzenmüller et al. (2015).

\section{2 | METHODS}

The assessment was conducted using a step-wise approach (Figure 1), devised by members of the ICES BEWG (BEWG, 2019), by modifying an existing assessment framework developed by the EU FP7 project MESMA (Monitoring Evaluation of Spatially Managed Areas) (Stelzenmüller et al., 2013). This framework was adapted to create a questionnaire that focused on three aspects: (i) did the benthos play an explicit role in the designation of the MPA; (ii) are management measures in place that directly target the benthos; and (iii) is there a monitoring programme in place that assesses the effectiveness of the protection measures for the benthos, using appropriate indicators and tools?

For this study, a group of 19 benthic experts were consulted in the development of the questionnaire, guidance notes, and data collection, who were all active members of the ICES BEWG and active benthic researchers and advisers (BEWG, 2019). Although these experts were experts in benthic ecology, they did not necessarily have specific expertise with MPA selection or management, which reduced any bias in the selection of the MPA case studies and the application of this framework. These experts were responsible for selecting the MPA case studies from their own ecoregion (see section 2.2) and collating the data required to complete the questionnaire (see section 2.3). These data were used to score the MPA case studies, using a pedigree matrix to enable numerical comparison.

\section{1 | Consensus of standard definitions}

Information for this questionnaire was derived from many sources (Table S2), and so standard definitions were agreed upon.

MPA: any area of the intertidal or subtidal terrain, together with its overlying water and associated flora, fauna, historical, and/or cultural features, which has been reserved by law or other effective means to protect part or all of the enclosed environment (IUCN, 2012).

Benthos: the benthos is comprised of all organisms that live at the bottom of a body of standing or running water. The layer that the benthos occupies is called the benthic zone, which is the lowest layer of a lake, sea, stream, or river. This zone ranges from the shallow depths, where water meets land, to extreme depths. Benthos can either be observed crawling, burrowing, swimming near the bottom, or staying attached to the substrate (Biologydictionary, 2019). For this study, the types of benthos include flora, infauna, epifauna, hyperfauna, bentho-pelagic fish, and their habitats.

\section{2 | MPA case study selection and validation}

The MPA case studies included in this assessment were primarily selected by the benthic experts for each ecoregion, based on the availability of both benthic experts from the ecoregions within the ICES BEWG (BEWG, 2019) and the availability of data. The most readily available data source for the assessment would have been for MPAs designated under the OSPAR/HELCOM guidelines; however, the authors concluded that a broad range of types of MPA, including fisheries protection areas and protected feeding areas for birds, would provide the best overall picture of how the benthos were represented and protected. Therefore, there was no requirement to intentionally select MPA case studies that had been designated specifically for the protection of the benthos. This selection process created a total of 102 MPA case studies from 10 countries spread over six ecoregions (Baltic Sea, Barents Sea, Celtic Sea, Greater North Sea, Norwegian Sea, and Western Mediterranean Sea; ICES, 2017) (Figure 2a; Tables 1 and S1). These case studies also included two Spanish sites that were on the border with France and were included in the French data to simplify the test for representativeness.

To ensure that the MPA case studies selected for this study were representative of all MPAs in each ecoregion, with regards to type, distribution, size, and position, the MPA case studies were compared with a full list of MPAs in the same ecoregions from a benchmark dataset: the World Database of Protected Areas (WDPA), a joint programme between the United Nations Environment Programme World Conservation Monitoring Centre (UNEP-WCMC) and the IUCN (UNEP-WCMC and IUCN, 2019). The WDPA database was downloaded and filtered to select for marine sites in the countries that contributed to this study (excluding any overseas territories). Also, terrestrial sites (e.g. landscape protection zones or protected dunes and sites where the terrestrial area was more than $80 \%$ of the reported whole site area), estuarine sites, and any duplicates (as a result of multiple designations for the same area) were removed by geographic information system (GIS) analysis. The remaining sites were then assigned to an ecoregion. The total number, percentage, and areal size per ecoregion of the contributory countries were calculated and compared based on this edited version of the WDPA database (WDPAe). At the ecoregion level, this study compiled data from about $10 \%$ of the MPAs listed in the WDPAe, except in the Barents 
FIGURE 1 Schematic diagram for the framework methodology (WDPA, World Database on Protected Areas)

\section{Research questions}

(i) Did the benthos play an explicit role in the designation of the MPA?

(ii) Are management measures in place that directly target benthos?

(iii) Is there a monitoring programme in place that assesses the effectiveness of the protection measures for the benthos?

\begin{tabular}{|c|c|c|}
\hline Analytical steps & Z & Achievements \\
\hline \multicolumn{3}{|c|}{ Framework and Definitions } \\
\hline $\begin{array}{l}\text { 1. Selection of an appropriate } \\
\text { framework }\end{array}$ & & $\begin{array}{l}\text { The EU FP7 project MESMA framework } \\
\text { was chosen (Stelzenmüller et al.,2013) }\end{array}$ \\
\hline 2. Consensus on standard definitions & $\Longrightarrow$ & Definitions of MPA and Benthos \\
\hline \multicolumn{3}{|c|}{ Case study selection and validation } \\
\hline $\begin{array}{l}\text { 3. Selection of benthic experts and case } \\
\text { studies based on availability of both } \\
\text { experts and data for each ecoregion }\end{array}$ & & $\begin{array}{l}19 \text { experts and } 102 \text { case studies from } \\
10 \text { countries and } 6 \text { ecoregions }\end{array}$ \\
\hline $\begin{array}{l}\text { 4. The selected MPA case studies were } \\
\text { compared with a benchmark dataset } \\
\text { (WDPA) }\end{array}$ & & $\begin{array}{l}\text { At the ecoregion level, data were } \\
\text { compiled from about } 10 \% \text { of the MPAs } \\
\text { listed in WDPA list (Table 1) }\end{array}$ \\
\hline $\begin{array}{l}\text { 5. GIS used to define categories based } \\
\text { on distance to the coast and depth to } \\
\text { determine representivity of case studies }\end{array}$ & & $\begin{array}{l}\text { Case study representation confirmed in } \\
4 \text { categories: coastal-shallow, coastal- } \\
\text { deep, offshore-shallow, offshore-deep }\end{array}$ \\
\hline \multicolumn{3}{|c|}{ Data collection } \\
\hline $\begin{array}{l}\text { 6. Development of a questionnaire } \\
\text { adapted from the MESMA framework }\end{array}$ & & $\begin{array}{l}19 \text { questions in } 4 \text { sections: metadata; } \\
\text { context; designation phase; } \\
\text { implementation phase (Table 2) }\end{array}$ \\
\hline 7. Creation of clear guidance notes & & Consistent interpretation of the questions \\
\hline $\begin{array}{l}\text { 8. Benthic experts collated data on the } \\
102 \text { selected MPA case studies }\end{array}$ & & $\begin{array}{l}\text { Data and information sources for all } 19 \\
\text { compiled into questionnaire spreadsheet }\end{array}$ \\
\hline $\begin{array}{l}\text { 9. Questions chosen to be included in } \\
\text { the summary criteria (Table } 3 \text { ) }\end{array}$ & & $\begin{array}{l}14 \text { summary criteria chosen and data } \\
\text { presented in a summary table (Supp. } \\
\text { Info., Tables } \$ 1 \text { and S2) }\end{array}$ \\
\hline & & \\
\hline \multicolumn{3}{|c|}{ Scoring of data } \\
\hline $\begin{array}{l}\text { 10. Quality criteria chosen to evaluate } \\
\text { and quantify the questionnaire responses }\end{array}$ & & 9 quality criteria chosen (Table 3 ) \\
\hline $\begin{array}{l}\text { 11. A numerical scale was devised to } \\
\text { assess the quality criteria responses for } \\
\text { the MPA case studies }\end{array}$ & & $\begin{array}{l}\text { Pedigree matrix (adapted from } \\
\text { Stelzenmüller et al.,2015) used to set a } \\
\text { numerical scale of score levels }(0-4) \\
\text { (Table 4) }\end{array}$ \\
\hline \multicolumn{3}{|r|}{ (rowic -4$)$} \\
\hline \multicolumn{3}{|c|}{$\begin{array}{l}\text { Quantification of benthos representation in MPAs } \\
\text { - Quantification of the questionnaire responses by scores } \\
\text { Statistical analyses of the representation and protection of the benthos in MPAs based } \\
\text { on scores } \\
\text { Results of the multivariate analyses of scores for the summary criteria interpreted and } \\
\text { consequences discussed }\end{array}$} \\
\hline
\end{tabular}

Sea and the Norwegian Sea (6 and 5\%, respectively) (Table 1). Although the numbers of MPA case studies in these ecoregions were equivalent to those in other ecoregions, these percentages were lower as there are a large number of small MPAs in these ecoregions, and comparing large numbers of small, very similar, MPAs would not be constructive. The GIS analysis also determined the distribution, depth, and position relative to the shore of the MPA case studies. There was good latitudinal distribution of the MPA case studies across European waters, from the north of Norway to Sardinia (Figure 2a), but there were some gaps in the geographic distribution of the case studies (e.g. the English Channel, some portions of the Western Mediterranean Sea, such as the south coast of Spain, the south-east coast of France, and the west coast of Italy, and the eastern portion of the Baltic Sea; Figure 2a) that arose from the lack of a representative expert from these areas.

All MPA size categories (i.e. $<1,1-10,10-100$, and $>100 \mathrm{~km}^{2}$ ) were present (Figure $2 \mathrm{~b}$ ). Although the majority of the MPA case studies (73\%) were coastal-shallow (i.e. $<12$ nautical miles from the 

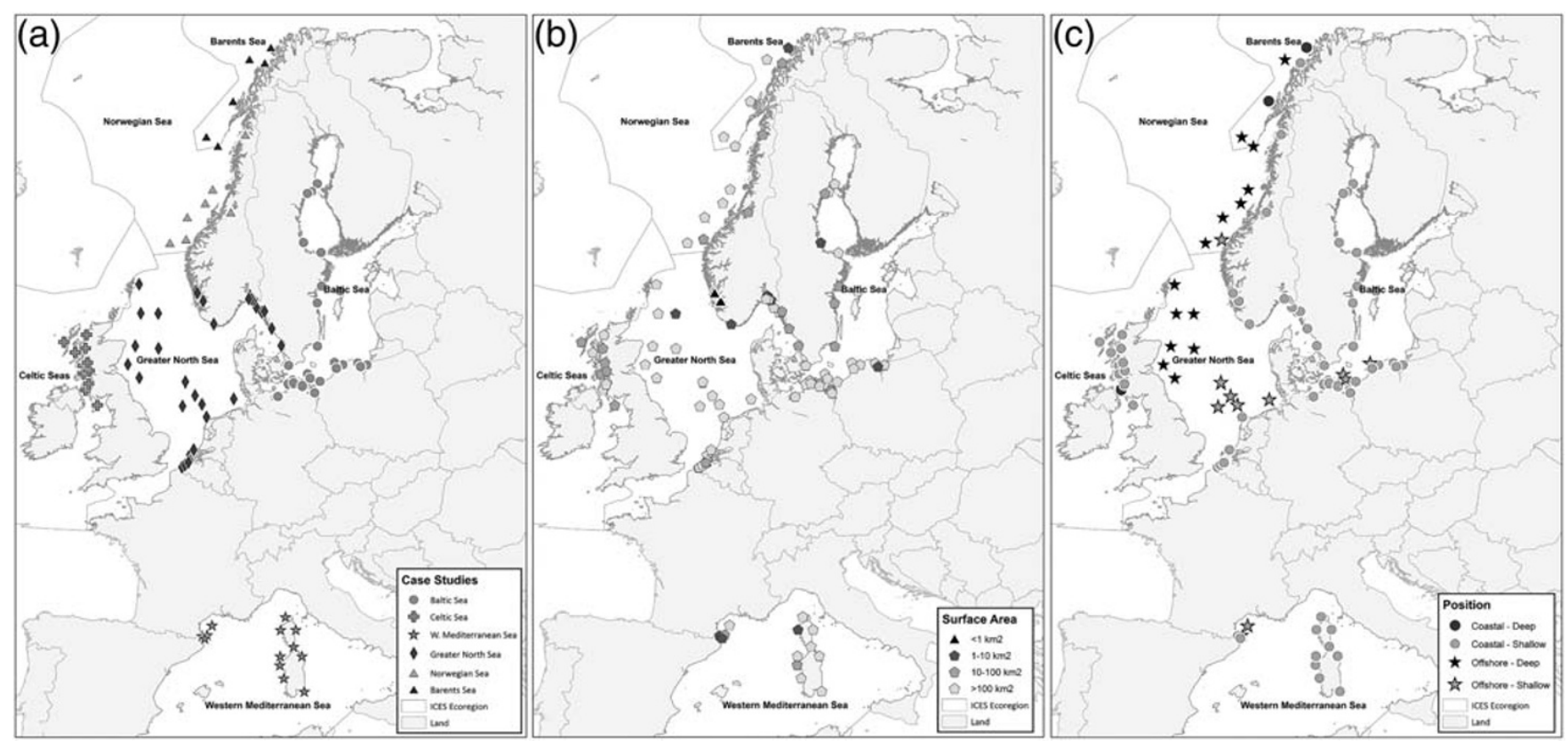

FIGURE 2 (a) Distribution of the 102 marine protected area (MPA) case studies and ecoregions considered in this study. (b) MPA case study surface areas (criterion $\mathrm{i}, \mathrm{km}^{2}$ ). (c) Position from coast (criterion iii, nautical miles): C, coastal ( $<12$ nautical miles); O, offshore ( $>12$ nautical miles). Depth (derived from GIS maps, $\mathrm{m}$ ): S, shallow (<50 m); D, deep (>50 m)

TABLE 1 Marine protected area (MPA) case studies in this study compared with data from an edited version of the World Database of Protected Areas (WDPAe) (UNEP-WCMC and IUCN, 2019)

\begin{tabular}{|c|c|c|c|c|c|c|c|c|}
\hline Region & Country & $\begin{array}{l}\text { No MPAs in } \\
\text { study }\end{array}$ & $\begin{array}{l}\text { No WDPA } \\
\text { MPAs }\end{array}$ & $\begin{array}{l}\text { \% WDPA } \\
\text { MPAs in } \\
\text { study }\end{array}$ & $\begin{array}{l}\% \text { MPA case } \\
\text { studies } \\
<1 \mathrm{~km}^{2}\end{array}$ & $\begin{array}{l}\% \text { WDPA } \\
\text { MPAs } \\
<1 \mathrm{~km}^{2}\end{array}$ & $\begin{array}{l}\% \text { MPA case } \\
\text { studies } \\
<10 \mathrm{~km}^{2}\end{array}$ & $\begin{array}{l}\% \text { WDPA } \\
\text { MPAs } \\
<10 \mathrm{~km}^{2}\end{array}$ \\
\hline \multirow[t]{3}{*}{ Baltic Sea } & All & 28 & 246 & 11 & 0 & 38 & 7 & 72 \\
\hline & Germany & 9 & 26 & 35 & 0 & 12 & 0 & 19 \\
\hline & Poland & 9 & 12 & 75 & 0 & 0 & 11 & 17 \\
\hline Celtic Sea & UK & 12 & 123 & 10 & 0 & 0 & 0 & 16 \\
\hline \multirow{3}{*}{$\begin{array}{l}\text { Western } \\
\quad \text { Mediterranean }\end{array}$} & All & 13 & 127 & 10 & 0 & 17 & 23 & 50 \\
\hline & Italy & 5 & 92 & 5 & 0 & 22 & 0 & 63 \\
\hline & France $^{b}$ & 8 & 35 & 23 & 0 & 3 & 38 & 17 \\
\hline \multirow{4}{*}{$\begin{array}{l}\text { Greater North } \\
\text { Sea }\end{array}$} & Netherlands ${ }^{a}$ & 8 & 5 & 160 & 0 & 0 & 0 & 0 \\
\hline & Germany & 0 & 7 & 0 & 0 & 0 & 0 & 14 \\
\hline & Norway & 10 & 260 & 4 & 30 & 89 & 80 & 97 \\
\hline & Sweden & 5 & 55 & 9 & 0 & 25 & 0 & 67 \\
\hline Norwegian Sea & Norway & 7 & 154 & 5 & 0 & 84 & 0 & 97 \\
\hline Totals & & 102 & 1,120 & 9 & 4 & 50 & 16 & 72 \\
\hline
\end{tabular}

Bold text indicates that these numbers are the totals for each ecoregion.

ancludes two Spanish sites that are on the border with France (Table S1).

'These regions included protected areas that were not in the WDPA. 
TAB LE 2 Questions developed and applied to collate data for the marine protected area (MPA) case-study questionnaire (adapted from Stelzenmüller et al., 2013)

\begin{tabular}{|c|c|c|c|}
\hline Section & Question & $\begin{array}{l}\text { Response } \\
\text { format }\end{array}$ & Guidance \\
\hline \multirow[t]{2}{*}{ (a) Metadata } & ICES ecoregion & & \\
\hline & Country & & \\
\hline \multirow[t]{3}{*}{ (b) Context setting } & i. Area coverage $\left(\mathrm{km}^{2}\right)$ & $\begin{array}{l}\text { Free text }(<100 \\
\text { words) }\end{array}$ & Converted to $\mathrm{km}^{2}$ for results \\
\hline & iii. Coordinates & $\begin{array}{l}\text { Free text }(<100 \\
\text { words) }\end{array}$ & For the 'central' point \\
\hline & $\begin{array}{l}\text { iv. Primary driver for the designation of } \\
\text { MPA }\end{array}$ & $\begin{array}{l}\text { Free text }(<100 \\
\text { words) }\end{array}$ & Legislation or, if not, conservation \\
\hline \multirow{3}{*}{$\begin{array}{l}\text { (c) Designation phase (existing data } \\
\text { and information available at time of } \\
\text { designation) }\end{array}$} & 2aii. Benthic information gathering tools & $\begin{array}{l}\text { Free text }(<100 \\
\quad \text { words })\end{array}$ & $\begin{array}{l}\text { List information tools, e.g. quantitative } \\
\text { surveys, habitat maps/Species } \\
\text { distribution models (SDMs), qualitative } \\
\text { surveys }\end{array}$ \\
\hline & $\begin{array}{l}\text { 2bi. Human activity conflict } \\
\text { analysis/overlap assessment } \\
\text { conducted }\end{array}$ & $\begin{array}{l}\text { Free text }(<100 \\
\text { words) }\end{array}$ & $\begin{array}{l}\text { Was a conflict analysis (overlap } \\
\text { assessment) conducted }\end{array}$ \\
\hline & 2bii. Number of activities identified & $\begin{array}{l}\text { Free text }(<100 \\
\quad \text { words })\end{array}$ & $\begin{array}{l}\text { Which and number of possible conflicts } \\
\text { of human activities on the benthos } \\
\text { were identified? }\end{array}$ \\
\hline \multirow[t]{4}{*}{$\begin{array}{l}\text { (d) Implementation phase (data and } \\
\text { information pertaining to current } \\
\text { situation for assessment and } \\
\text { monitoring) }\end{array}$} & 3. Benthic indicators (or descriptors) & $\begin{array}{l}\text { Free text }(<100 \\
\text { words) }\end{array}$ & $\begin{array}{l}\text { What indicators for measuring } \\
\text { management effectiveness have been } \\
\text { chosen, identified, or withheld? None } \\
\text { or in development acceptable }\end{array}$ \\
\hline & 4a. Assessment of state of the benthos & Drop-down list & $\begin{array}{l}\text { What if any tools were used to assess } \\
\text { the state of the benthos, e.g. detailed } \\
\text { survey, habitat mapping, data from } \\
\text { secondary sources, such as by-catch } \\
\text { data? }\end{array}$ \\
\hline & 4b. Monitoring of the benthos & $\begin{array}{l}\text { Free text }(<100 \\
\text { words) }\end{array}$ & $\begin{array}{l}\text { Were data on the benthos collected } \\
\text { through monitoring programmes or } \\
\text { dedicated studies to assess the } \\
\text { management effectiveness (e.g. } \\
\text { through the selected indicators)? }\end{array}$ \\
\hline & 5. Auditing & Drop-down list & $\begin{array}{l}\text { Were the data on the benthos collected } \\
\text { in step } 4 \text { assessed against the }\end{array}$ \\
\hline
\end{tabular}


TABLE 2 (Continued)

\begin{tabular}{|c|c|c|c|}
\hline \multirow[t]{3}{*}{ Section } & Question & $\begin{array}{l}\text { Response } \\
\text { format }\end{array}$ & Guidance \\
\hline & & & $\begin{array}{l}\text { anticipated effect of the management } \\
\text { measures, i.e. is it 'fit for purpose'? }\end{array}$ \\
\hline & 6. Adaptation & Drop-down list & $\begin{array}{l}\text { Did/does the monitoring } \\
\text { strategy/management plan include a } \\
\text { process for changing the management } \\
\text { plan, indicators, monitoring, etc.? }\end{array}$ \\
\hline & 7. Literature/v & & \\
\hline
\end{tabular}

shore and $<50 \mathrm{~m}$ in depth), there were case studies from all the other position-depth categories: i.e. coastal-deep (three MPAs; <12 nautical miles from the shore and $>50 \mathrm{~m}$ in depth), offshore-shallow (10 MPAs; $>12$ nautical miles from the shore and $<50 \mathrm{~m}$ in depth), and offshore-deep (15 MPAs; >12 nautical miles from the shore and $>50 \mathrm{~m}$ in depth) (Figure 2c). Thus, the case studies selected for this study were deemed to be a pragmatic but representative sample of the MPAs in these ecoregions.

\section{3 | Data collection}

The evidence-gathering exercises were conducted by benthic experts of the ICES BEWG in 2017. All data for the MPA case studies chosen for this study were collected for further analysis, using a questionnaire, and then recorded in a spreadsheet (Table S1). In addition, the sources used to derive the data were also recorded (Table S2). These sources included legal documents, official policy documents, published reports, and peer-reviewed articles.

The questionnaire was based on a framework developed by the EU FP7 project MESMA (Stelzenmüller et al., 2013) to enable the monitoring and evaluation of spatially managed marine areas in a standardized way. The MESMA framework consisted of seven overarching steps. For this study, the assessment was based on three of these steps, and the associated substeps: (i) context setting; (ii) the availability of existing information; and (iii) assessment and evaluation. These steps and substeps of the MESMA framework were adapted to incorporate key elements of MPA selection that may alter the effectiveness of an MPA to protect the benthos within it. Questions and clear guidance notes were formulated and adjusted to ensure an unambiguous interpretation of the questions. This resulted in 19 questions, differentiated by four sections: (a) metadata; (b) context setting (size, position, year of MPA designation, and primary legislative driver); (c) designation phase (existing data and information that were available at the time of designation); and (d) implementation phase (data and information pertaining to the current situation for assessment and monitoring) (Table 2).

After the questionnaire was completed, the question responses were collated by the two lead authors and summarized into 14 summary criteria (Table 3 ). These summary criteria were differentiated by: context (criteria i-iv); designation phase (criteria 1a-2d); and implementation phase (criteria 3-4b). The full summary data and information sources used are listed in Table S1, and were used to add context when interpreting the data. The summary criteria for the designation phase included information on whether the benthos was considered in the original designation of the MPA, which benthos were included, and how this information was collected. These are important because accurate baseline data are essential for onward monitoring and assessment and to ensure that the species and habitats of primary importance for conservation are represented. Also, the designation criteria included information on the impact of human activities on the benthos and any management/conservation measures present. It is important to consider these at the designation phase because human activities that could be damaging to the protected species or habitats should be recorded at the outset, to ensure that relevant mitigating measures can be applied.

In order to express the quality of the responses to the questionnaire on a numerical scale that would facilitate further analyses, the pedigree matrix approach from Stelzenmüller et al. (2015) was chosen and adapted. A pedigree matrix provides distinct definitions for selected quality criteria spread over a numerical scale or scoring levels. In this study the pedigree matrix was based on nine quality criteria, selected from the original 14 summary criteria (Table 3). Two of these quality criteria, 'Benthic ecosystem components and tools' (criterion 2a) and 'Impact of human activities on the benthos' (criterion 2b) used data combined from multiple questions (Tables 2 and S1). Definitions for the nine quality criteria for score levels 0-4 (0, low quality; 4 , high quality) were determined (Table 4). These definitions and scoring levels were defined, refined, and agreed upon during discussions at ICES BEWG annual meetings. Scores were based on levels from Edgar et al. (2014) for size and Rodríguez-Rodríguez, Sciberras, Foster, and Attrill (2015) for general guidance for setting the scaling levels for the monitoring and assessment criteria. The range of scores for the designation phase (five criteria, $1 \mathrm{a}-2 \mathrm{~d}$ ) and the implementation phase (three criteria, 3-4b) were 0-20 and 0-12, respectively. These scores enabled the quantification and analysis of the questionnaire responses (the full results are listed in Table S3), and allowed the data to be interrogated separately depending on the phase.

\section{4 | Statistical analysis}

The data were visualized as histograms using $R$ ( $R$ Core Team, 2013) and box plots using SIGMA PLOT 10 (Systat Software Inc., San Jose, CA) 


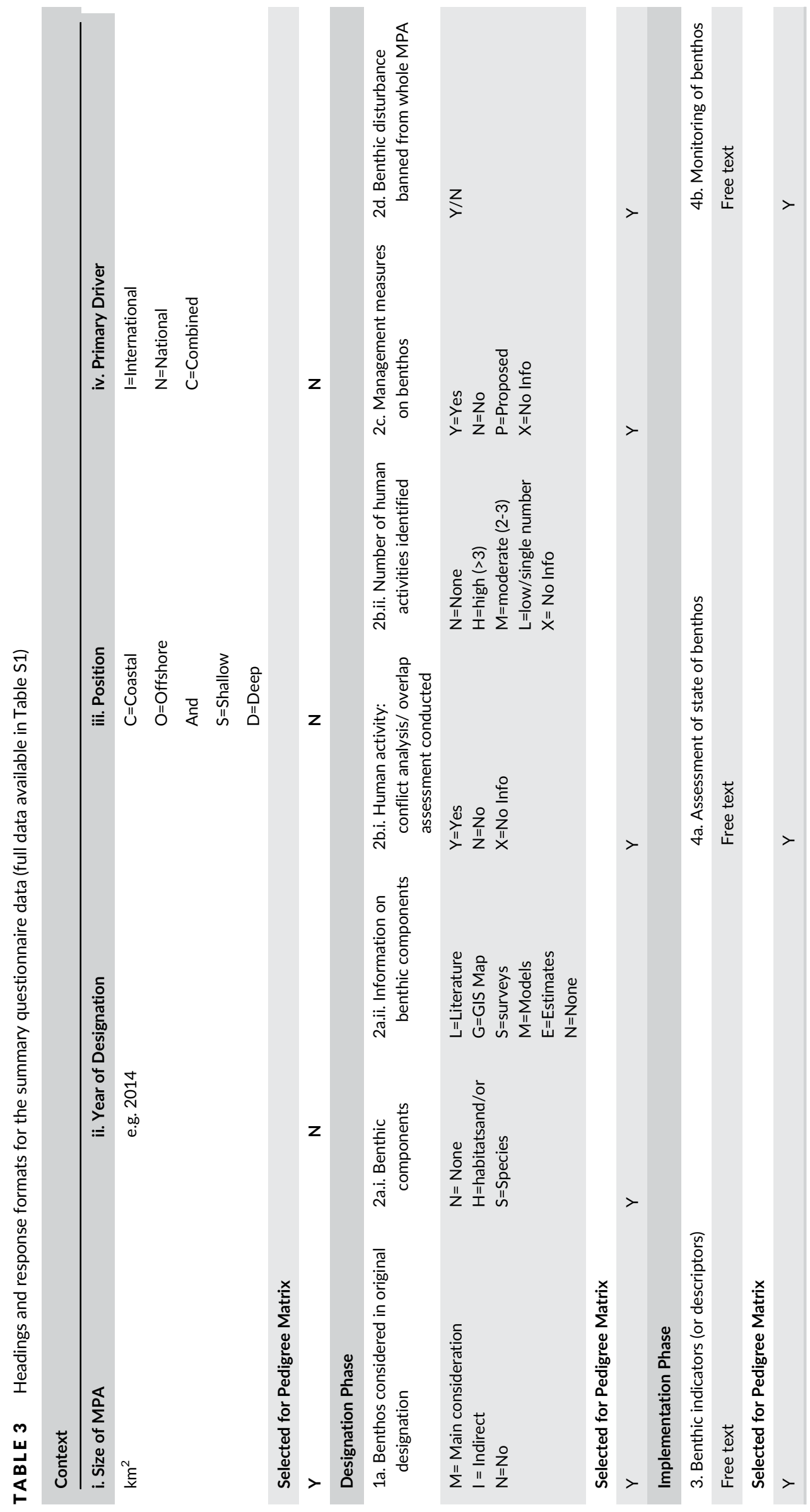




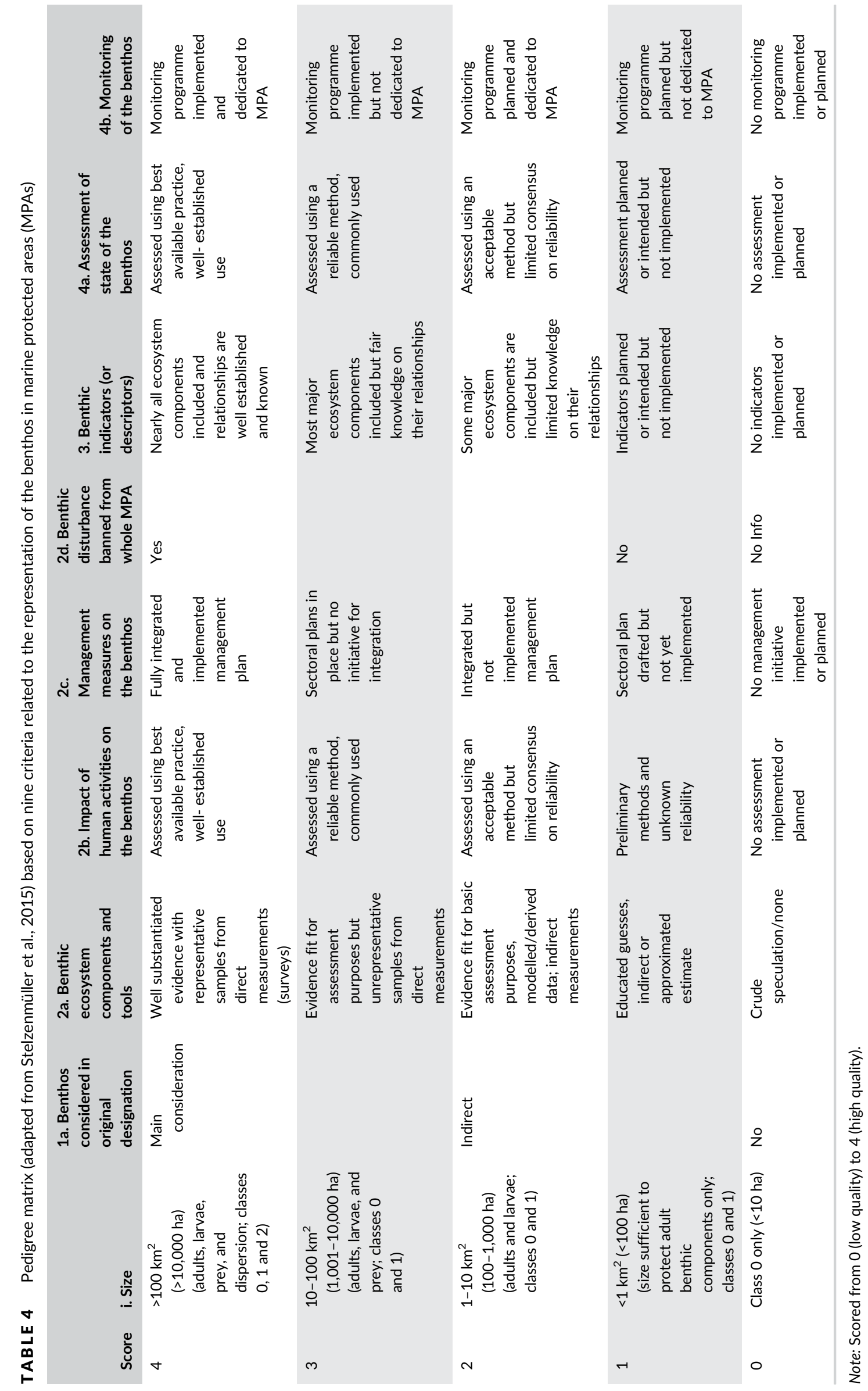


and analysed using multivariate techniques. All multivariate analyses were performed using PRIMER-E 6 (PRIMER-e, 2006). The multivariate techniques were applied to an overarching analysis of the dataset for both the designation and the implementation phases. As the dataset had different ranges of scores, data were normalized to ensure equal importance for criteria in the designation phase and implementation phase. The results were visualized using non-metric multidimensional scaling (nMDS). Also, multivariate one-way analysis of similarities (ANOSIM) was used to determine the significance of differences between scores for each MPA case study in different ecoregions in both the designation and the implementation phases (Clarke \& Gorley, 2006). Resemblance matrices were based on Euclidean distance similarities between individual MPA case studies. To identify the contributions of different criteria to possible differences between ecoregions for the designation phase and the implementation phase, analyses of similarity percentages (SIMPER) were performed (Clarke \& Gorley, 2006). The test for multivariate dispersion (MVDISP) was used to describe relative multivariate dispersion within each of the ecoregions, based on the Euclidean distance resemblance matrix

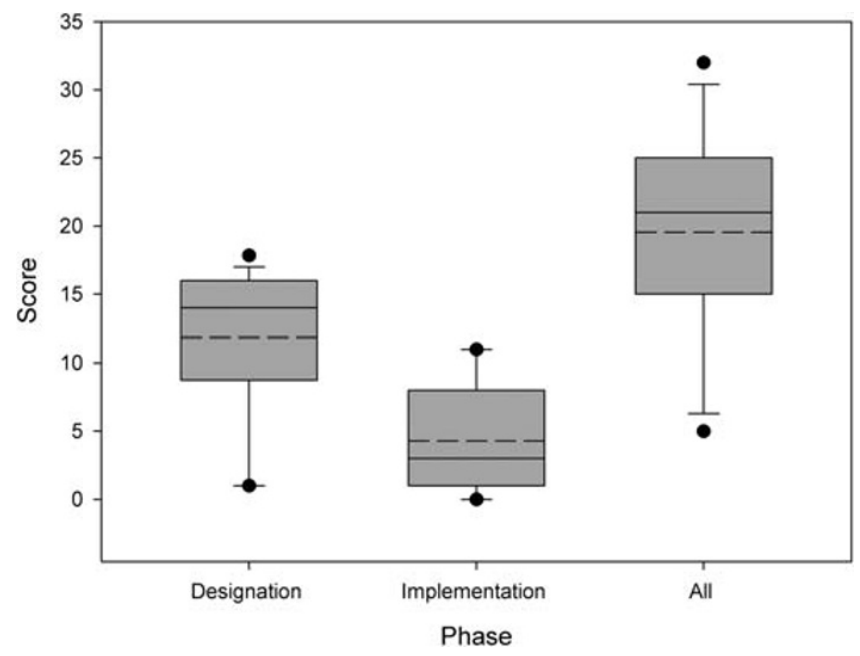

FIGURE 3 The relationship between marine protected area (MPA) case study scores and phase. Median values, solid lines; mean values, dashed lines; fifth and $95^{\text {th }}$ percentiles and outliers are displayed; designation phase, criteria 1a-2d; implementation phase, criteria 3-4b; all, criteria i, 1a-2d and 3-4b
(Clarke, Gorley, Somerfield, \& Warwick, 2014). A low value for MVDISP signifies low variability.

\section{3 | RESULTS}

Overall, the results of the scoring exercise show that the relationship between all MPA case study criteria scores and phase is highly variable (Table S3): the scores ranged from the lowest possible scores to the highest possible in both the designation and the implementation phases (Figure 3). Also, the median value was higher than the mean in the designation phase (data skewed to the right) but was lower than the mean in the implementation phase (data skewed to the left) (Figure 3). This was also indicated by a higher percentage of MPA case studies at the higher end of the range of scores (i.e. with scores of 3 or 4 ) in the designation phase (criteria 1a-2d) than in the implementation phase (criteria 3-4b) (Figure 4).

\section{1 | MPA context: Size, year of designation, and legislative drivers}

Although all of the MPA size categories (i.e. <1, 1-10, 10-100, and $>100 \mathrm{~km}^{2}$ ) were present, it is notable that $16 \%$ of the MPA case studies were smaller than $10 \mathrm{~km}^{2}\left(4 \%,<1 \mathrm{~km}^{2}\right)$ (Table 1$)$. This was mainly through a large proportion of MPA case studies in Norway, Sweden, and the UK being smaller than $10 \mathrm{~km}^{2}$ (Table 1). Of the 102 MPA case studies, $14 \%$ had a combination of primary legislative drivers associated with them (Table S1). The $41 \%$ of MPA case studies that were identified as having only international drivers were primarily designated under the Habitats Directive (Natura 2000) and/or CBD MPAs (i.e. OSPAR, HELCOM, and BC) (Table S1). The $45 \%$ of MPA case studies that were identified as only having national drivers tended to be nature reserves designated under national legislation (NNRs), fisheries protection areas, and areas in non-EU countries that were not signatories to the Habitats Directive (Table S1).

There was a wide range of 'year of designation' for the MPA case studies, ranging from 1974 (France) to 2017 (UK) (Figure 5; Table S1). The high variation in scores recorded in all ecoregions, for both the implementation and designation phases, ranged over the whole time
FIGURE 4 Frequency of marine protected area (MPA) case studies for each total score for (a) designation phase (criteria $1 \mathrm{a}-2 \mathrm{~d}$ ) and (b) implementation phase (criteria $3-4 b$ ), as a percentage of all MPA case studies considered in this study. Dashed lines indicate the values for the total high scores (3-4) for all criteria

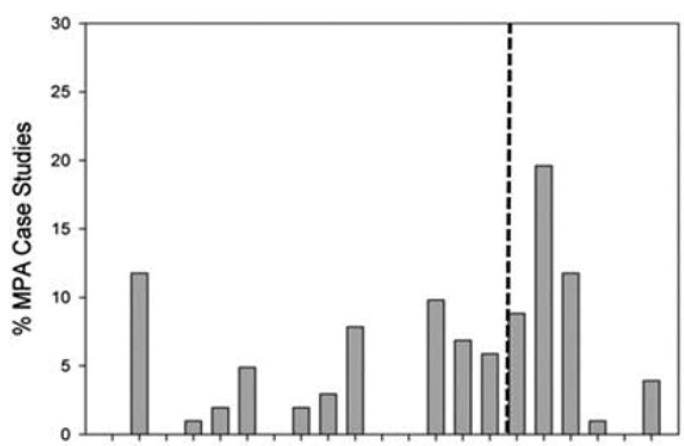

(a)
012344567891011121314151617181920 Score

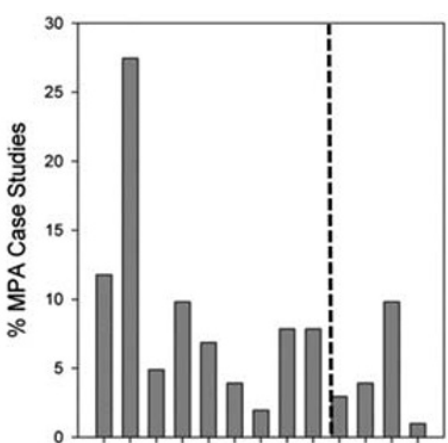

(b) $\begin{array}{lllllllllll}0 & 1 & 2 & 3 & 4 & 5 & 6 & 7 & 8 & 9 & 101112\end{array}$ Score 

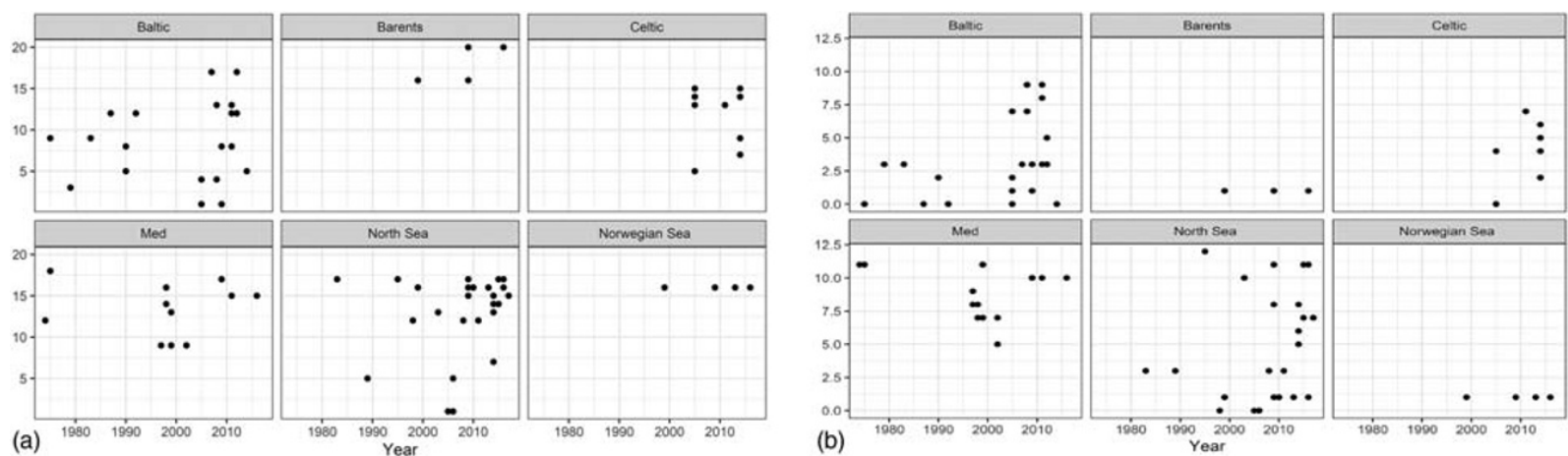

FIGURE 5 Effect of year of designation on the total scores for (a) designation phase (criteria 1a-2d) and (b) implementation phase (criteria 3-4b). Range from 1974 (France) to 2017 (UK)

period (Figure 5); however, the highest scores were generally obtained for MPAs designated after 2010 (i.e. after the current Aichi Biodiversity Target 11 was set; CBD, 2010).

\subsection{Did the benthos play an explicit role in the designation of the MPA?}

This question is covered by scores from the designation phase criteria 1a, 2ai, and 2aii (Table 2). Four of the six ecoregions recorded 'benthos' as the main consideration for designating the MPA ( $72 \%$ of the MPA case studies in criterion 1a scored 4); however, some MPAs did not consider the benthos at all (42\% of MPA case studies from the Baltic Sea; 16\% from the Greater North Sea) (Figure 6a). There was a lot of variation in the type and quality (assessed by the pedigree matrix) of the information on the benthos used for the initial designation of the MPA case studies (criteria 2ai and 2aii), ranging from poorquality tools that provided data on a limited number of components (scores of 0-1) to high-quality surveys covering all of the ecosystem components present (scores of 3-4) (Figure 6b). The full dataset, used to inform the results of the pedigree matrix (Table S1), shows that $50 \%$ of the MPA case studies combine collecting information on both benthic habitats and benthic species with the use of a range of highquality tools for characterization to achieve maximum scores of 4 for criteria 2ai and 2aii.

\subsection{Are management measures in place that directly target the benthos?}

This question is covered by scores from the designation-phase criteria 2bi, 2bii, 2c, and 2d (Table 2). Initial impact assessments of human activities on the benthos were conducted in $84 \%$ of the MPA case studies (criterion 2bi, Table S1), but only $58 \%$ were assessed using high-quality methods (scored 3-4, Table S3), mainly in the Barents Sea, Celtic Sea, and Norwegian Sea. The combined information from these two subcriteria resulted in a high proportion of maximum scores (3-4) in only three of the ecoregions (Barents Sea, Celtic Sea, and Norwegian Sea) (Figure 7a). Management and/or conservation measures related to the benthos (criterion $2 \mathrm{c}$ ) were generally applied to some degree in most of the ecoregions (Figure 7b). These mainly included fishing restrictions, but in other areas where tourism is the predominant pressure, this included restrictions on boat anchoring and the recreational harvesting of shellfish (Table S1). In the Baltic
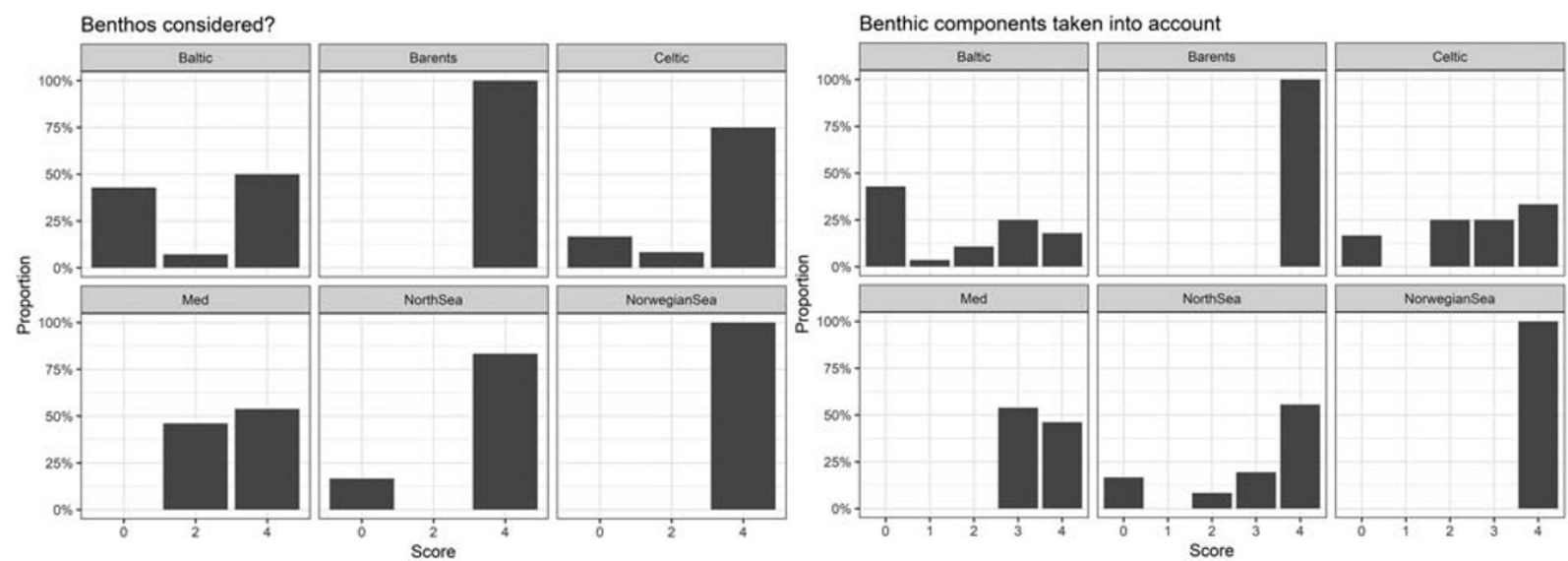

FIGURE 6 Did the benthos play an explicit role in the designation of the marine protected area (MPA)? Frequency of MPA case studies for each designation criteria score by ecoregion, as a percentage of all case studies considered within each ecoregion: (a) criterion 1a, benthos considered in original designation; and (b) criterion 2a, benthic ecosystem components and tools (scores combined information from criterion $2 a \mathrm{i}$ and 2aii; Table 2) 

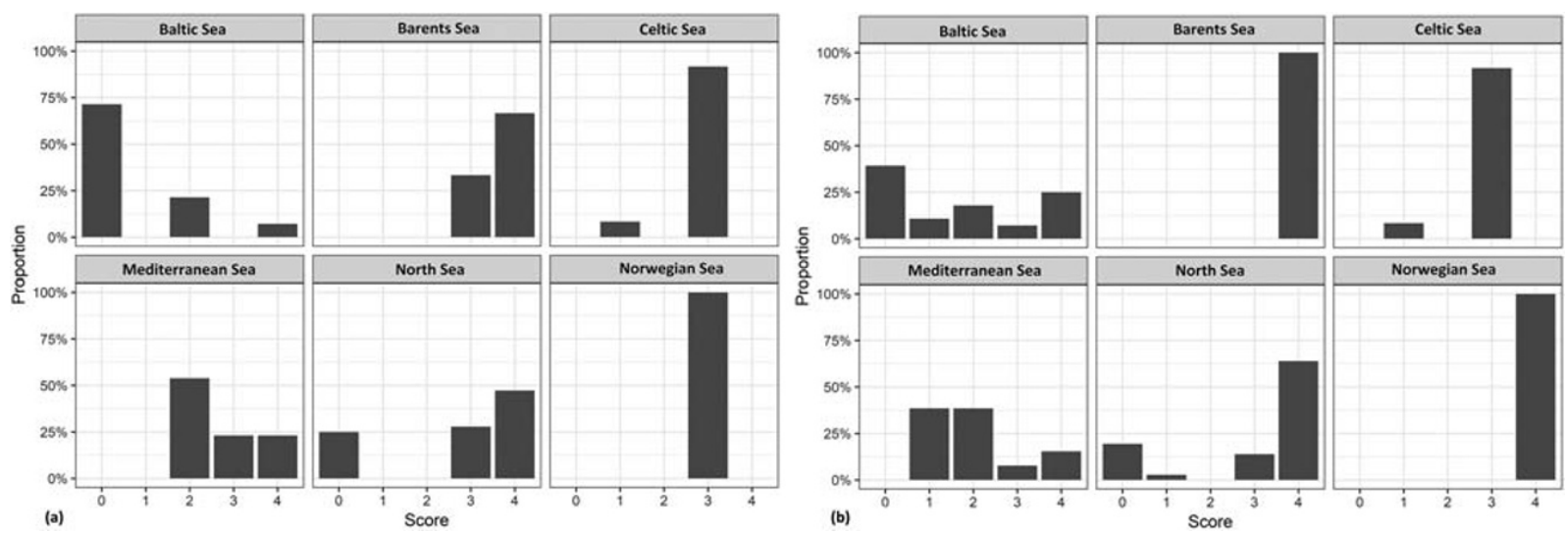

FIGURE 7 Are management measures in place that directly target the benthos? Frequency of marine protected area (MPA) case studies for designation criteria score by ecoregion, as a percentage of all case studies considered within each ecoregion: (a) criterion $2 b$, impact of human activities on benthos (scores combined information from criterion $2 \mathrm{bi}$ and $2 \mathrm{bii}$; Table 2); and (b) criterion $2 \mathrm{c}$, management measures on benthos

Sea, however, $46 \%$ of the case studies recorded that no benthosfocused management measures had been applied (Figure 7b). Benthic disturbance was banned from the whole MPA (criterion $2 \mathrm{~d}$ ) in only $6 \%$ of the MPA case studies, mainly from the Barents Sea and the Western Mediterranean (67\% of MPAs in the Barents Sea and 15\% of MPAs in the Western Mediterranean Sea) (Table S3).

\subsection{Is there a monitoring programme that assesses the effectiveness of the management measures for the benthos?}

This question is covered by the scores for the implementation phase criteria 3, 4a, and $4 b$ (Table 2). The scores for the implementation phase were generally in a lower range than the designation phase (Figure 4). In four of the six ecoregions, scores for the use of benthic indicators (criterion 3, Figure 8a) and the assessment of the state of the benthos (criterion 4a, Figure 8b) were generally low, with $71 \%$ of all MPA case studies with scores of less than or equal to 2 in both of these criteria. High scores ( 3 or 4 ) for these criteria were reached for a comparatively higher number of case studies in only two ecoregions: the Western Mediterranean Sea and the Greater North Sea. Scores for the monitoring of the benthos (criterion $4 b$, Figure $8 c$ ) were generally higher, indicating that monitoring programmes have been implemented in at least some MPAs in most of the ecoregions, except for the Barents Sea and the Norwegian Sea, where there were none. Maximum values (3 or 4) for monitoring, however, were reached only for MPA case studies in the Western Mediterranean Sea and in the Greater North Sea (Figure 8c).

\subsection{Are there differences in the designation and implementation of MPAs between ecoregions?}

In the designation phase, the multivariate analysis of the scores for the different criteria in each MPA case study revealed significant differences between the ecoregions (one-way ANOSIM, $R=0.189$, $P=0.001$; Table 5). Pairwise comparisons revealed the strongest differences between scores for the Barents Sea and scores obtained for all other ecoregions. No large differences were observed between any of the other ecoregions (Figure 9a; Table 5). SIMPER indicates that the main contributing factor to the difference between the Barents Sea and the other ecoregions was criterion $2 \mathrm{~d}$, assessing whether benthic disturbance is banned from the whole MPA (Table S4).

The multivariate analysis of the scores for the implementation phase between ecoregions also differed significantly (one-way ANOSIM, $R=0.098, P=0.006$; Table 6). The largest pairwise differences were recorded for comparisons involving the Western Mediterranean Sea and the Celtic Sea with the other ecoregions (Figure 9b; Table 6). SIMPER indicates that the main contributing factor to the differences between the Western Mediterranean Sea and the other ecoregions was criterion 3 (benthic indicators); the main contributing factor to the differences between the Celtic Sea and the other ecoregions was criterion $4 \mathrm{~b}$ (monitoring of the benthos) (Table S4).

The test for multivariate dispersion (MVDISP; Table 7) indicates that in the designation phase the Baltic Sea had the highest degree of relative dispersion (1.13) and the Norwegian Sea had the lowest (0.15). In the implementation phase the Greater North Sea had the highest degree of relative dispersion (1.15) and the Norwegian Sea and the Barents Sea had the lowest (0.16). The most marked difference between the designation and implementation phases was for the Barents Sea (0.98 and 0.16, respectively).

These analyses of variation in dispersion within the MPA case studies of each ecoregion confirm that the highly significant differences observed between the Barents Sea and other ecoregions in the designation phase (Table 5) were not driven by variation in the MPA case studies as a whole, but by high variation in specific criteria (e.g. criterion $2 \mathrm{~d}$, assessing whether benthic disturbance is banned from the whole MPA, and criterion 2c, management measures on benthos, as indicated by the SIMPER analysis) within the case studies: i.e. $R>0.4, P \leq 0.001$ (Table 5) and MVDISP > 0.7 (Table 7). In the implementation phase the highly significant differences between the 

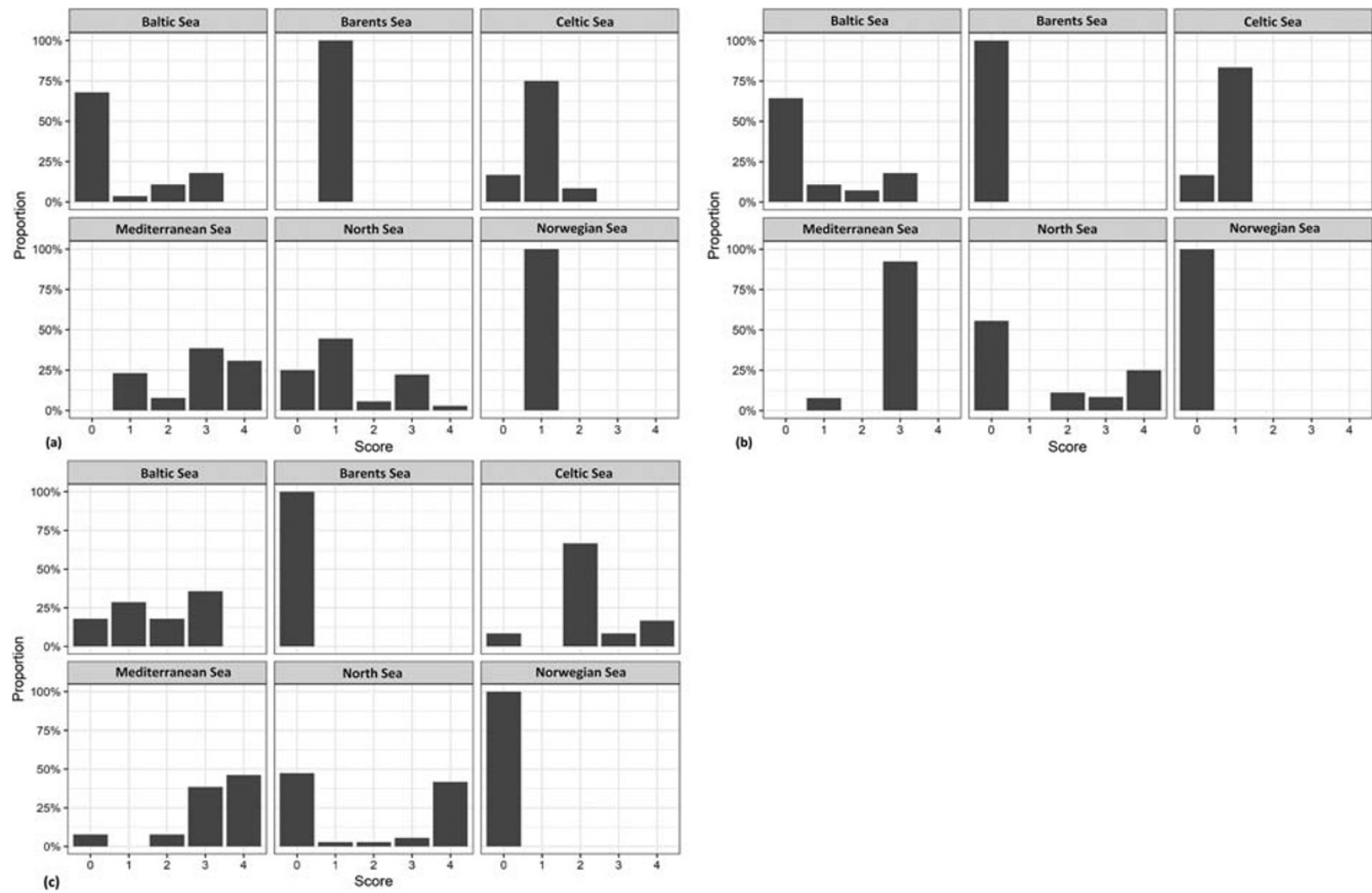

(b)

Score

FIGURE 8 Is there a monitoring programme that assesses the effectiveness of the management measures for the benthos? Frequency of marine protected area (MPA) case studies for each implementation criteria score by ecoregion, as a percentage of all case studies considered within each ecoregion: (a) criterion 3 , benthic indicators; (b) criterion $4 \mathrm{a}$, assessment of state of the benthos; and (c) criterion $4 \mathrm{~b}$, monitoring of the benthos

TABLE 5 One-way analysis of similarities (ANOSIM) comparing the criteria scores in the designation phase with 'ecoregion' as the grouping factor

\begin{tabular}{|lll|}
\hline Designation phase & \multicolumn{1}{l}{$\boldsymbol{R}$} \\
\hline Global & 0.189 & 0.001 \\
\hline Baltic Sea, Barents Sea & 0.717 & 0.001 \\
\hline Barents Sea, Celtic Sea & 0.647 & 0.001 \\
\hline Barents Sea, Norwegian Sea & 0.444 & 0.019 \\
\hline Barents Sea, Western Mediterranean Sea & 0.443 & 0.007 \\
\hline Barents Sea, Greater North Sea & 0.383 & 0.011 \\
\hline Baltic Sea, Norwegian Sea & 0.262 & 0.002 \\
\hline Baltic Sea, Greater North Sea & 0.256 & 0.001 \\
\hline Western Mediterranean Sea, Norwegian & 0.22 & 0.042 \\
\hline Sea & & \\
\hline Celtic Sea, Norwegian Sea & 0.199 & 0.065 \\
\hline Baltic Sea, Western Mediterranean Sea & 0.165 & 0.022 \\
\hline Western Mediterranean Sea, Greater & 0.165 & 0.043 \\
\hline North Sea & & \\
\hline Baltic Sea, Celtic Sea & 0.142 & 0.012 \\
\hline Celtic Sea, Western Mediterranean Sea & 0.137 & 0.015 \\
\hline Celtic Sea, Greater North Sea & 0.02 & 0.369 \\
\hline Greater North Sea, Norwegian Sea & -0.23 & 0.998 \\
\hline
\end{tabular}

Note: Numbers in bold indicate the strongest differences.
Western Mediterranean Sea and the Celtic Sea and the other ecoregions (i.e. high $R$ values, $P \leq 0.001$; Table 6 ) were driven by variation in the MPA case studies as a whole and not by differences in specific criteria within the case studies, corroborated by a relatively even contribution of all criteria to the pairwise comparisons (from SIMPER analysis, Table S4) and high dispersion between MPA case studies (MVDISP > 0.7, Table 7).

\section{4 | DISCUSSION}

There are other existing and continuing initiatives to document the progress and effectiveness of MPAs (Agnesi et al., 2017; Buhl-Mortensen et al., 2017; Hatton-Ellis et al., 2012; HELCOM, 2013; Horta-e-Costa et al., 2016; McDermott et al., 2017; OSPAR, 2007, 2008; Pomeroy et al., 2004; Staub \& Hatziolos, 2004; Stelzenmüller et al., 2013; Stolton \& Dudley, 2016); however, these initiatives have taken different approaches, compared with the method selected in this study. Also, these initiatives have not differentiated between ecosystem components, specifically the benthos. Therefore, this study is unique, as it is the first examination of the representation and protection of the benthos in the designation and management of MPAs, using a standardized framework supported by evidence-based case studies. 


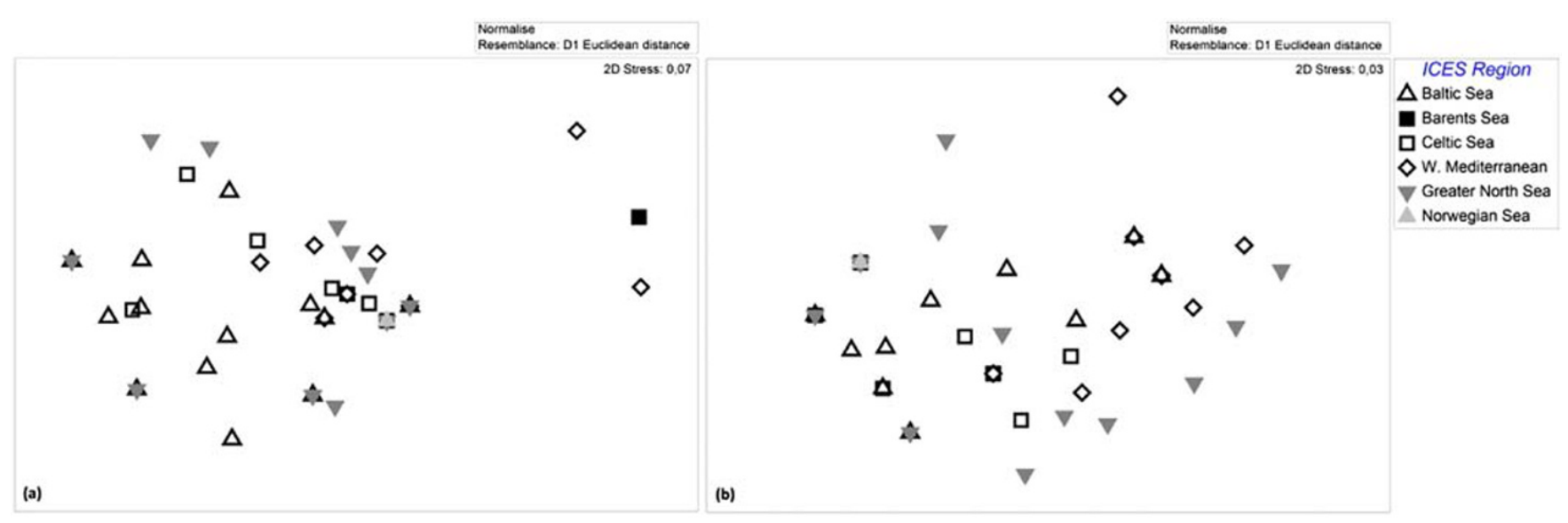

FIGURE 9 Are there differences in the designation and implementation of marine protected areas (MPAs) between ecoregions? nMDS plots of MPA case studies differentiated by: (a) designation-phase criteria scores; and (b) implementation-phase criteria scores

TAB LE 6 One-way analysis of similarities (ANOSIM) comparing the criteria scores in the implementation phase with 'ecoregion' as the grouping factor

\begin{tabular}{|lll|}
\hline Implementation phase & \multicolumn{1}{l}{$\boldsymbol{R}$} \\
\hline Global & 0.098 & 0.006 \\
\hline $\begin{array}{l}\text { Western Mediterranean Sea, } \\
\quad \text { Norwegian Sea }\end{array}$ & 0.925 & 0.001 \\
\hline Barents Sea, Western Mediterranean Sea & 0.921 & 0.001 \\
\hline Celtic Sea, Western Mediterranean Sea & 0.636 & 0.001 \\
\hline Celtic Sea, Norwegian Sea & 0.631 & 0.001 \\
\hline Barents Sea, Celtic Sea & 0.604 & 0.001 \\
\hline Baltic Sea, Western Mediterranean Sea & 0.478 & 0.001 \\
\hline Western Mediterranean Sea, Greater & 0.149 & 0.005 \\
\hline North Sea & & \\
\hline Baltic Sea, Greater North Sea & 0.044 & 0.059 \\
\hline Baltic Sea, Norwegian Sea & 0.031 & 0.317 \\
\hline Baltic Sea, Celtic Sea & 0.028 & 0.26 \\
\hline Baltic Sea, Barents Sea & 0.016 & 0.345 \\
\hline Barents Sea, Norwegian Sea & 0 & 1 \\
\hline Celtic Sea, Greater North Sea & -0.092 & 0.978 \\
\hline Greater North Sea, Norwegian Sea & -0.134 & 0.996 \\
\hline Barents Sea, Greater North Sea & -0.142 & 0.994 \\
\hline
\end{tabular}

Note: Numbers in bold indicate the strongest differences.

The MPA case studies included in this study were selected rather pragmatically but following an approach that reduced any potential bias. This resulted in the inclusion of a wide variety of MPAs, with a representative selection of case studies for each region. Notwithstanding a lack of data from the English Channel, the eastern part of the Baltic Sea and several parts of the Western Mediterranean Sea (south coast of Spain, east coast of France, and west coast of Italy), the exercise has successfully compiled and compared data from approximately $10 \%$ of the MPAs listed in the edited WDPAe database. Also, a range of legislative drivers, regional projects, and organizations from MAREANO (MAREANO, 2019) in the far north, and from HELCOM, OSPAR, and the Barcelona Convention in the south, as well as a large latitudinal range were covered. The gaps in geographical coverage were caused by the lack of representatives from these areas among the expert group, rather than by any bias in selection. The authors acknowledge, however, that if more information from a larger selection of MPAs were collected and more datasets became available, this would help to strengthen the analysis and help to provide a more detailed overview of the selection of MPAs, and their management and monitoring. This could possibly enable the tracking of the progress of an MPA towards full implementation.

Generally, the results showed that there was a high degree of variation in the methods used for the designation of MPAs, the assessment and management of human activities, and how any changes in the state of the benthos were monitored and assessed. Also, the results show that the regional differences were not consistent between the designation and implementation phases. In the designation phase, the Barents Sea and the Norwegian Sea had the greatest differences compared with the other ecoregions, attributable to the consistent use of good-quality methods for characterizing the benthos present. In the implementation phase, the Western Mediterranean Sea had the greatest differences with the other ecoregions, mainly linked to the use of good-quality indicators for the monitoring and assessment of the MPAs in this ecoregion. In other ecoregions, the mismatch of lower scores for the implementation phase criteria compared with the designation phase could be linked to greater resource allocation in the designation phase, and the slower implementation of monitoring and assessment.

\subsection{Did the benthos play an explicit role in the designation of the MPA?}

The benthos was the main consideration in the designation of the majority of the MPAs assessed in this study (72\%); however, the benthos did not play an explicit role in the designation of a considerable proportion of MPAs (28\%). This could be detrimental to the eventual 
TAB LE 7 The test for multivariate dispersion (MVDISP) showing the relative dispersion of the marine protected area (MPA) case studies in the ecoregions

\begin{tabular}{|lllll} 
& $\begin{array}{l}\text { Relative dispersion in } \\
\text { designation phase }\end{array}$ & $\begin{array}{l}\text { Degree of relative } \\
\text { dispersion }\end{array}$ & $\begin{array}{l}\text { Relative dispersion in } \\
\text { implementation phase }\end{array}$ & $\begin{array}{l}\text { Degree of relative } \\
\text { dispersion }\end{array}$ \\
\hline Baltic Sea & 1.13 & ++++ & 0.94 & ++++ \\
\hline Barents Sea & 0.98 & ++++ & 0.16 & ++ \\
\hline Celtic Sea & 0.78 & +++ & 0.56 & +15 \\
\hline Greater North Sea & 0.97 & ++++ & 0.16 & +++ \\
\hline Norwegian Sea & 0.15 & + & 0.84 & + \\
\hline $\begin{array}{l}\text { Western } \\
\text { Mediterranean Sea }\end{array}$ & 0.99 & ++++ & & +++ \\
\hline
\end{tabular}

Degree of relative dispersion: +, low dispersion ( $\leq 0.4)$; ++, medium dispersion (>0.4); +++, high dispersion (>0.7); ++++, very high dispersion (>0.9).

success of an MPA, considering that the benthos provides important ecological roles, such as food provision, shelter, and nursery areas for many protected fish, birds, and mammals (Bonsdorff \& Blomqvist, 1993; Buhl-Mortensen et al., 2010; Galparsoro et al., 2014; Kent et al., 2016). Although the authors appreciate that including the benthos is not practical for some MPAs (e.g. large areas in offshore waters for marine mammal protection), this finding could strengthen the argument that the benthos should be given more consideration, particularly for their role in ecosystem functioning, during the designation of new MPAs. Most of the ecoregions, especially the Norwegian Sea and the Barents Sea, have used good-quality methods (e.g. surveys) to quantify the benthic components of the MPA (64\% of MPA case studies). Such good-quality assessments, undertaken at the designation phase, ensure that the species and habitats of primary importance for conservation are represented, in accordance with OSPAR guidelines (OSPAR, 2007), and that accurate baseline data are available for onward monitoring and assessment. As more diverse habitats tend to be more resilient (Ardron, 2008; Craig \& Hughes, 2014; Palumbi, 2003; Shanks, 2009), knowledge on the diversity of species and habitats in an MPA allows an assessment of its likely resilience to anthropogenic pressures. In addition, highlighting that the benthos have an important role in providing ecosystem services (both social and economic) may help to gain the societal and governmental support required for an MPA to achieve its conservation objectives (Klein et al., 2015).

Current policy recommendations are to fully protect at least $30 \%$ of marine habitats to maximize the benefits of MPAs (O'Leary et al., 2016). Considering that currently only $5.3 \%$ of the world's ocean is protected in actively managed marine protected areas, there is a long way to go (MPAtlas, 2020). Also, the at least $30 \%$ target is open to misinterpretation, as it does not specify which habitats are to be protected, and protecting $30 \%$ of the surface area of a regional sea for marine mammals is very different to actively protecting $30 \%$ of the seabed for the benthos. This could be exacerbated by the sparsity of data on the distribution of the benthos.

Another important issue for the benthos is the size of the MPA or, more specifically, the size of the area within an MPA that is protected from adverse human activities. This has considerable influence on whether the MPA will be successful in protecting the benthos within it (Ballantine, 2014; Claudet et al., 2008; Edgar et al., 2014; Planes et al., 2000; Vandeperre et al., 2011). Specific small-scale MPAs may be useful for protecting localized benthic species, such as cold-water coral reefs; however, they are potentially ecologically insufficient as they do little to prevent degradation and damage to the wider ecosystem that these species depend upon (Agardy, Notarbartolo di Sciara, \& Christie, 2011). Larger MPAs have the potential to protect wider support systems (e.g. the influx of food resources, increased habitat diversity and edge habitats, source-sink dynamics for larval dispersion, and reduced predation pressure) that are important for the resilience of species and habitats to anthropogenic pressures (Ardron, 2008; Craig \& Hughes, 2014; Palumbi, 2003; Shanks, 2009). MPAs would be deemed to be of sufficient size within a wider network, if, for example, they facilitated the larval dispersal and settlement of benthic species by ensuring that habitats and refugia are available for all life stages within a protected environment, and that adequate food resources are also available within the protected zones (Frid et al., 2008; Jonsson, Moksnes, Corell, Bonsdorff, \& Nilsson Jacobi, 2020; Laffoley et al., 2008; Shanks, 2009). Not providing adequate space around the target species or habitats for the protection of these wider support systems in MPAs may lead to the failure of the MPA to reach its intended objectives. In addition, small patches of benthic habitats, such as biogenic reefs or seagrass beds, may be particularly susceptible to destructive influences from nature, such as storms (Ballantine, 2014; Edgar et al., 2014; Planes et al., 2000), which would be exacerbated by anthropogenic pressures (Hiddink, Hutton, Jennings, \& Kaiser, 2006). Large numbers of small MPAs that displace fishing effort may increase the likelihood that detrimental effects of fishing outside the MPA will have an impact on the species and habitats inside the MPA (Hiddink et al., 2006; Jones, Srinivasan, \& Almany, 2007). For example, in Lyme Bay (UK), small fishery closures were ineffective in protecting the small areas of biogenic reef, and it was considered necessary to also protect a larger area surrounding the reefs; the exclusion of bottom fishing in a larger area made the recovery of the reefs achievable (Stevens, Sheehan, Gall, Fowell, \& Attrill, 2014). 


\subsection{Were management measures in place that directly target the marine benthos?}

Very few of the MPA case studies $(<6 \%)$ were designated as areas where benthic disturbance is banned from the whole MPA ('no-take'), which was also identified by SIMPER as the main difference between ecoregions in the designation phase. This was mainly driven by the four MPAs in the Barents Sea and two MPAs in the Western Mediterranean where benthic disturbance is banned from the whole MPA, and could indicate that in these ecoregions the protection of the whole MPA from benthic disturbance was considered appropriate. Also, as these MPAs tended to be smaller, a whole MPA ban on benthic disturbance could be considered to be more feasible with regards to enforcement. There are only a few studies into the effects of 'notake' zones on the benthos, e.g. the Adriatic Sea (De Biasi \& Pacciardi, 2008), the Ebro Delta (De Juan, Demestre, \& Sanchez, 2011), the Mediterranean Sea (Coppa et al., 2016), and the Barents Sea (Buhl-Mortensen, 2017). A couple of studies, however, have examined the effect of different management actions on conservation outcomes for the benthos (Ban, McDougal, Beck, Salomon, \& Cripps, 2014; McConnaughey et al., 2020; Mills et al., 2011). Ban et al. (2014) proposed that marine areas that had strong protection measures (IUCN categories I-II, 'no-take') had higher biodiversity conservation effectiveness indices than MPAs with lesser IUCN categories (i.e. categories IV and $\mathrm{VI}$ ). Also, areas that allowed different levels of resource extraction and disturbance only achieved $10 \%$ of their conservation objectives for benthic ecosystems (Mills et al., 2011). Therefore, an MPA that uses zonal management measures as protection from physical anthropogenic pressures, such as benthic trawling or anchoring, may have limited benefits. These may prevent further local degradation of the benthos of interest but may not secure the maintenance and recovery of wider populations (Jessen et al., 2017). In addition, the ecological effectiveness of different management actions varies depending on the species or the ecosystem (Dichmont et al., 2013; Mills et al., 2011). This is because species-specific traits, such as life-cycle attributes, recruitment and migration, trophic interactions, and species interactions, affect how benthic species or habitats respond to different anthropogenic pressures (Farina et al., 2018; Frid et al., 2008). Therefore, to successfully protect the benthos, these 'ecological factors' should be considered in management actions, and will require different approaches to fulfil protection and conservation objectives (Gill et al., 2017; Shanks, 2009).

There was a lot of variation in how the impacts of human activities on the benthos were assessed and managed in the MPA case studies. Some regions (the Celtic Sea and the Norwegian Sea) have used good-quality analyses of human activity conflicts, and overlap assessments, and have management measures in place. For other ecoregions, however, especially the Baltic Sea, this is a work in progress. Poor-quality mapping of human activities and overlap assessments of anthropogenic pressures with vulnerable benthos in the designation phase are potential risk factors for effective protection. For example, if the potential for displacement of fishing effort from an MPA is not identified and mitigated, the effects of this displacement fishing may detract from any observed benefits of the MPA as a result of increased fishing pressure in virgin or other underexploited areas outside the MPA (Hiddink et al., 2006; McConnaughey et al., 2020; McDermott et al., 2017). Although the complete banning of benthic disturbance from the whole MPA is considered to be one of the most effective methods for protecting the benthos within it, very few MPA management schemes have considered this to be a viable option.

\subsection{Were the monitoring programmes in place supported by appropriate indicators and tools to assess the effectiveness of any management measures for the benthos?}

Good-quality assessments of the benthos in the designation phase were not generally followed up with good-quality monitoring and assessment programmes for the benthos in the implementation phase (71\% of MPA case studies). This indicates that at the time of this study, two-thirds of the MPA case studies showed an inconsistent use of appropriate MPA-scale indicators and an inadequate assessment of the state of the benthos. This mismatch opposes the generally accepted opinion that good-quality initial data leads to good-quality monitoring and assessment (Loh et al., 2019). This possibly results from the slow application of assessment and monitoring programmes or from fewer resources being applied to the implementation phases in the majority of the MPA case studies. The Western Mediterranean Sea was the main exception to this, because of good scores in the designation phase that were replicated for indicators and assessments in the implementation phase. A coherent and efficient spatial sampling design for the benthos in all phases is essential to achieve more accurate status assessments (Van Hoey et al., 2019). Also, it would be logical to assume that setting up robust survey and sampling methods and analyses that produce accurate baseline data during the designation phase of an MPA would improve the likelihood of effective monitoring and assessment of the MPA in the future, as any significant changes are more likely to be identified precisely and accurately (Van Hoey et al., 2019).

Although the scores for the monitoring of the benthos were generally higher than the scores for the indicator and assessment criteria (except for the Barents Sea and the Norwegian Sea, which scored 0 in all cases), possibly as a result of monitoring programmes instigated under the Habitats Directive or Water Framework Directive (Table S1), there was generally poor spatial and temporal coverage of monitoring within the MPA case studies. The Norwegian Sea and Barents Sea scored zero for monitoring of the benthos because although habitat extents were mapped during the designation phase (MAREANO, 2019), this has not been followed up with assessment and monitoring in the implementation phase. It is generally considered to be poor practice to consider an ecological component of a management scheme important but then to not monitor it at an appropriate spatio-temporal scale, or to use poor-quality indicators and targets (Loh et al., 2019). This could result in monitoring schemes that are ineffective for detecting any change in the benthos as a result of MPA 
management (Loh et al., 2019). Also, this could manifest as low confidence in assessments of whether the conservation objectives of an MPA have been met, where the key issues are and may exacerbate uncertainty with regards to the effects of any management measures implemented. These observations could either be a symptom of a continuing process or could be an indicator that these MPAs only have 'paper protection', where the high expectations of management plans and guidance documents are not reflected in the field.

These inconsistences indicate areas where work is required to reduce the risk of MPAs failing to reach their objectives. This is pertinent because of the considerable work on indicators and assessments already achieved by initiatives such as OSPAR and HELCOM, specifically for MPAs (OSPAR, 2016). Also, the scarcity of resources available to support assessment and monitoring should drive more cost-effective methods.

\section{4 | Legislative framework}

This study deliberately included MPA case studies originating from a range of primary drivers, from NNRs and EU Directives through to fisheries protection legislation. This has meant that a range of considerations of the benthos was exhibited, from locally important benthic species or habitats being the primary focus of MPAs designated under NNR legislation, to the broad habitats and internationally important species defined in the Habitats Directive, but also the benthos protected as a secondary component of fisheries management areas under the Common Fisheries Policy or special feeding areas under the Birds Directive. This shows that the benthos can be protected by indirect methods, such as the Clyde Sea Sill (CE01), designated for black guillemots, and the Plaice Box (NS31), a fisheries management measure. This range of MPA legislations have resulted in diverse interpretations of how and/or which components of the benthos are protected in MPAs, which is reflected in the wide variation in scores from the designation phase. Also, this complex legislative and policy landscape could possibly lead to confusion over assessment and monitoring requirements, conservation objectives, the protected features represented, a lack of clarity in the use of specific MPA terminology, and in multiple different designations for the same section of sea.

Although some ecoregions, in particular the Baltic Sea, have a high proportion of low scores across all criteria, this could be explained by the fact that the process of selection and designation of MPAs may be at an earlier stage than in other ecoregions. This is balanced by poorer than expected performance in most other ecoregions that started the process earlier (e.g. the Celtic Sea and the Greater North Sea), especially with regard to assessments and monitoring. There have been shifts in MPA policy over the years, with significant changes introduced by the Habitat's Directive and CBD in 1992, the MSFD in 2008, and the Marine Spatial Planning Directive in 2014. These may have caused delays to MPA development as a result of the time required for transcription into existing and new national regulations, and the development of guidelines and frameworks to deliver the required objectives. In particular, the implementation of MSFD has changed how MPA managers are applying monitoring, environmental targets, and management measures to MPA management. This temporal change or progression in MPA development was highlighted by higher scores in most of the MPA case studies that were designated more recently (i.e. post 2010 , Figure 5). This could also be linked to differences in the requirements of the legislative drivers: long-standing NNRs may not have the same monitoring and assessment requirements as sites designated under the Habitats Directive (1992) or the OSPAR MPA recommendation (2003). This changing legislative landscape has also yielded more prescriptive requirements for the selection, monitoring, and reporting of MPAs (Wells et al., 2016). For example, the selection of OSPAR MPAs was based on detailed ecological criteria, first defined in 2003 in the guidelines provided by the OSPAR Commission for the identification and selection of MPAs (OSPAR, 2003), and was then updated in 2007. Also, the setting of CBD Aichi MPA targets in 2010 has led to a greater number of MPA designations after this date (more MPAs, more scores). Temporal progression also brings greater experience, more data, and more knowledge. The low numbers of high scores associated with earlier MPA case studies could also reflect that there was a slow uptake of MPA designation: by 2006 , only six OSPAR contracting parties reported progress in the nomination of sites to be considered as components of the OSPAR network (Lutchman et al., 2008). In particular, the Baltic Sea scores have been affected by this as it started designating MPAs under the CBD much later than other ecoregions.

The inclusion of sites that are not fully implemented (e.g. no active effective monitoring and assessment in place) in official government statistics can inflate the perception of how much of, and how well, the ocean is protected. Although it could be disingenuous to completely dismiss MPAs that are not fully implemented, there is a risk that the inclusion of these MPAs in statistics could hide information on MPAs that remain unimplemented for extended periods of time or indefinitely. These MPAs could therefore be considered 'paper parks'; however, we hypothesize that the large variation in scores demonstrated in this study is a symptom of a continuing process that will improve with time as the use of MPAs as a management tool is developed further, and this could be tested by repeating this study at a future date.

Although a large number of sites were considered and a large volume of information has been presented in this paper, the authors are aware that they are not exhaustive and not fully representative for some countries and ecoregions. Therefore, looking forward, it would be useful to study a wider range of regions, including tropical regions, for comparison, and a few case studies in more detail to highlight specific issues. These could include functional diversity and ecological functions as the main drivers of ecosystem stability and recovery, and how these are recognized in the the designation and implementation of MPAs. Also, the IUCN-WCPA Green List Standard could be used as a framework to create an effectiveness index for each MPA, with regard to the benthos (IUCN, 2019). To support the findings in this study, a joint report by the Institute for European Environmental Policy (Brussels, Belgium) and Natural Resources Defence Council 
(Washington DC, USA) (Lutchman et al., 2008) also highlighted similar concerns, defined as four key barriers to the implementation of MPAs: lack of evidence; common terminology; detailed objectives for nature conservation; and a mismatch of competences.

\section{5 | CONCLUSIONS}

This study has contributed new knowledge to the study of the benthos in MPAs. Our study has highlighted inconsistencies and risk factors to the representation and protection of the benthos in the present MPA process, which will need to be addressed.

Poor consideration and characterization of benthic ecosystem components, and their wider ecological requirements, during baseline investigations in the designation phase could decrease the effectiveness of the future assessment and monitoring of the MPA.

The size of an MPA is an important consideration, particularly if it is to protect a patchwork of small habitat areas (e.g. biogenic reefs), as protecting each small area of habitat alone may not be sufficient to safeguard its resilience to both natural and anthropogenic pressures. A large MPA is also more likely to ensure that the wider support systems for benthic species and habitats are also found within a protected environment.

Fully protected areas are more effective than partially protected areas (zonal protection), producing greater benefits in terms of biodiversity conservation and productivity. Good-quality mapping of human activities and the potential overlaps of human activity with vulnerable benthos in the initial phases of an MPA are important to identify and mitigate for the effects of anthropogenic pressures inside the MPA, and the displacement of these pressures (e.g. fishing) outside the MPA. In addition, species-specific traits affect the ecological effectiveness of different management actions and are therefore important considerations for management measures.

Effective protection of the benthos is dependent on a coherent process that applies accurate and robust methods and analyses throughout the designation and implementation of MPAs. Ineffective monitoring and assessment programmes caused by the application of poor-quality indicators and targets at an inappropriate spatiotemporal scale could result in the poor detection of any change in the benthos as a result of the management of an MPA. The effectiveness of management measures could be increased if the role of the benthos in ecosystem functioning is considered when designing and implementing monitoring and assessment programmes.

The complex legislative and policy landscape surrounding the designation and implementation of MPAs may have contributed to the high proportion of low scores across all criteria in some regions and delays in the full implementation of some MPAs. Also, this complexity could potentially lead to confusion over assessment and monitoring requirements, conservation objectives, and the protected features represented, and to a lack of clarity in the use of specific MPA terminology. Some MPAs with indefinite delays in the full implementation of management measures, and assessment and monitoring programmes, could be considered 'paper parks', however. If this study is repeated in 5-6 years it may be possible to identify these so-called 'paper parks'.

Our work has also highlighted some good practice: fine-scale habitat mapping; central, easily navigated repositories for information pertaining to MPAs; and unified processes that allowed areas designated under different legislation to be easily cross-referenced and integrated into new legislative and policy objectives (i.e. assessment against MPA selection guidelines, including the identification of priority features, data-confidence assessments, and management options papers).

\section{6 | RECOMMENDATIONS}

1 Current policy recommendations are to fully protect at least $30 \%$ of marine habitats to maximize the benefits of MPAs (O'Leary et al., 2016). This target could be misinterpreted and fulfilled with only pelagic habitats for the protection of marine mammals, for example. With their important role in marine ecosystems, specific targets for the benthos should be specified within this overarching ambition.

2 It is highly recommended that the designation of MPAs for the benthos is based on good baseline knowledge of the species and habitats present. Therefore, MPAs should use good-quality tools (e.g. high-resolution characterization surveys) to quantify the benthic components considered in the designation of MPAs and that adequate management plans, assessments, and monitoring are used to evaluate the effectiveness of the MPA in meeting conservation objectives.

3 To ensure that MPAs are of sufficient size to include wider support systems for the benthos (e.g. adequate food resources, habitats, and refugia available for all life stages), the ecological requirements of both the species and habitats of interest and any wider support systems should be considered at the MPA designation phase, by including this in MPA selection guidelines.

4 The issue of the displacement of fishing effort from an MPA is an important factor that should be considered at the designation phase with regards to the size and position of an MPA. In particular, it may be worth considering combining lots of small MPAs into fewer, larger MPAs if they cover a patchwork of small habitat areas.

5 Guidelines should be introduced that strongly recommend that MPAs should have benthic disturbance removed from the whole MPA.

6 Risk assessments and experimental investigations of how species and habitats respond to different levels of management should be undertaken to ensure the correct application of management measures (Dichmont et al., 2013; Mills et al., 2011).

7 Overarching guidance should be developed to encompass all types of MPAs, possibly following the IUCN-WCPA Green List Standard to: 'Encourage protected and conserved areas to measure, improve and maintain their performance through globally consistent criteria that benchmark good governance, sound design and planning, 
effective management, and successful conservation outcomes' (IUCN, 2019).

8 Further investigations into cost-effective and applicable monitoring practices within MPAs are needed, to assess whether they actually deliver benefits to marine benthic ecosystems compared with areas outside the network. Therefore, OSPAR, HELCOM, the Barcelona Convention, and the IUCN should facilitate the sharing of knowledge between contracting parties and the development of overarching guidance on cost-effective monitoring programmes.

\section{ACKNOWLEDGEMENTS}

This publication was initiated and facilitated by the Benthos Ecology Working Group (BEWG), which is an expert group of the International Council for the Exploration of the Sea (ICES). We gratefully acknowledge all BEWG colleagues who participated in discussions, during the BEWG annual meetings, to develop the questionnaire and pedigree matrix. We would also like to thank: Vittorio Gazale (Director of the Asinara MPA, Sardinia); Ana Jesus and Zoe Gutteridge (JNCC, UK); Simone Farina (IMC, Oristano, Italy); Victòria Riera Aragó (Director of Parc Natural de Cap Creus, Spain); and Marta Tykarska (Institute of Oceanography, University of Gdansk, Poland) for their help with data collation and additional discussions. Finally, we gratefully acknowledge the constructive feedback provided by the Editor in Chief of Aquatic Conservation (Professor John M. Baxter) and the anonymous reviewers' comments for their further suggestions and constructive comments to improve this article.

\section{ORCID}

Clare Greathead (D) https://orcid.org/0000-0001-7411-4359

Paolo Magni (D) https://orcid.org/0000-0001-5955-6829

Lene Buhl-Mortensen (D) https://orcid.org/0000-0003-0530-7119

Mats Blomqvist (iD https://orcid.org/0000-0001-5387-0438

Johan A. Craeymeersch (D) https://orcid.org/0000-0002-3053-4906

Jennifer Dannheim (D) https://orcid.org/0000-0002-3737-5872

Nicolas Desroy (iD) https://orcid.org/0000-0002-9047-5637

Ivan Guala (D) https://orcid.org/0000-0003-4712-1435

Celine Labrune (D) https://orcid.org/0000-0002-8470-347X

Silvana N.R. Birchenough (D) https://orcid.org/0000-0001-5321-8108

\section{REFERENCES}

Abou-Elela, G. M., Abd-Elnaby, H., Ibrahim, H. A. H., \& Okbah, M. A. (2009). Marine natural products and their potential applications as anti-infective agents. World Applied Sciences Journal, 7, 872-880. https://doi.org/10.1016/s1473-3099(03)00655-8

Agardy, T., Notarbartolo di Sciara, G., \& Christie, P. (2011). Mind the gap: Addressing the shortcomings of marine protected areas through large scale marine spatial planning. Marine Policy, 35, 226-232. https://doi. org/10.1016/j.marpol.2010.10.006

Agnesi, S., Mo, G., Annunziatellis, A., Chaniotis, P., Korpinen, S., Snoj, L., \& Globevnik, L. (2017). Assessing Europe's marine protected area networks-Proposed methodologies and scenarios. In A. Künitzer (Ed.), ETC/ICM technical report 2/2017 (p. 72). Magdeburg: European Topic Centre on inland, coastal and marine waters.

Amengual, J., \& Alvarez-Berastegui, D. (2018). A critical evaluation of the Aichi Biodiversity Target 11 and the Mediterranean MPA network, two years ahead of its deadline. Biological Conservation, 225, 187-196. https://doi.org/10.1016/j.biocon.2018.06.032

Ardron, J. A. (2008). Three initial OSPAR tests of ecological coherence: Heuristics in a data-limited situation. ICES Journal of Marine Science, 65, 1527-1533. https://doi.org/10.1093/icesjms/fsn111

Ballantine, B. (2014). Fifty years on: Lessons from marine reserves in New Zealand and principles for a worldwide network. Biological Conservation, 176, 297-307. https://doi.org/10.1016/j.biocon.2014. 01.014

Ban, N. C., McDougal, I. C., Beck, M., Salomon, A. K., \& Cripps, K. (2014). Applying empirical estimates of marine protected area effectiveness to assess conservation plans in British Columbia, Canada. Biological Conservation, 180, 134-148. https://doi.org/10.1016/j.biocon.2014. 09.037

Barbier, E. B., Hacker, S. D., Kennedy, C., Koch, E. W., Stier, A. C., \& Silliman, B. R. (2011). The value of estuarine and coastal ecosystem services. Ecological Monographs, 81, 169-193. https://doi.org/10. 1890/10-1510.1

Barcelona Convention. (1995). The Barcelona Convention for the protection of the marine environment and the coastal region of the Mediterranean, protocol concerning specially protected areas and biological diversity in the Mediterranean. Available at: https://web. unep.org/unepmap/who-we-are/legal-framework [Accessed 06 April 2020]

Beaumont, N. J., Austen, M. C., Atkins, J. P., Burdon, D., Degraer, S., Dentinho, T. P., ... Zarzycki, T. (2007). Identification, definition and quantification of goods and services provided by marine biodiversity: Implications for the ecosystem approach. Marine Pollution Bulletin, 54, 253-265. https://doi.org/10.1016/j.marpolbul.2006.12.003

Beukema, J. J. (1995). The long-term effects of mechanical harvesting of lugworms on the zoo-benthos community of a tidal flat in the Wadden Sea. Netherlands Journal of Sea Research, 33, 219-227. https://doi.org/ 10.1016/0077-7579(95)90008-X

BEWG. (2019). The International Council for the Exploration of the Sea, Benthic Ecology Working Group members. Available at: https://www. ices.dk/community/groups/Pages/Members.aspx?Acronym=BEWG

Biologydictionary.net Editors. "Benthos" Biologydictionary.net. May 2019. Available at: https://biologydictionary.net/organ/ [Accessed 06 April 2020].

Birchenough, S. N. R., Parker, E. R., McManus, E., \& Barry, J. (2012). Combining bioturbation and redox metrics: Potential tools for assessing seabed function. Ecological Indicators, 12, 8-16. https://doi.org/10. 1016/j.ecolind.2011.03.015

Bonsdorff, E., \& Blomqvist, E. M. (1993). Biotic Coupling on shallow water bottoms-Examples from the northern Baltic Sea. In Oceanography and Marine Biology, An Annual Review (Vol. 31) (pp. 153-176).

Buhl-Mortensen, L., Galparsoro, I., Vega-Fernández, T., Johnson, K., D'Anna, G., Badalamenti, F., ... Vanaverbeke, J. (2017). Maritime ecosystem-based management in practice: Lessons learned from the application of a generic spatial planning framework in Europe. Marine Policy, 75, 174-186. https://doi.org/10.1016/j.marpol.2016.01.024

Buhl-Mortensen, L., Vanreusel, A., Gooday, A. J., Levin, L. A., Priede, I. G., Buhl-Mortensen, P., ... Raes, M. (2010). Biological structures as a source of habitat heterogeneity and biodiversity on the deep ocean margins. Marine Ecology, 31, 21-50. https://doi.org/10.1111/j.14390485.2010.00359.x

Buhl-Mortensen, P. (2017). Coral reefs in the Southern Barents Sea: Habitat description and the effects of bottom fishing. Marine Biology Research, 13, 1027-1040. https://doi.org/10.1080/17451000.2017. 1331040

Clarke, K. R., \& Gorley, R. N. (2006). PRIMER version 6: User manual/tutorial. Plymouth, UK: PRIMER-E.

Clarke, K. R., Gorley, R. N., Somerfield, P. J., \& Warwick, R. M. (2014). Change in marine communities: An approach to statistical analysis and interpretation (3rd ed.). Plymouth, UK: Primer-E Itd. 
Claudet, J., Osenberg, C. W., Benedetti-Cecchi, L., Domenici, P., GarcíaCharton, J. A., Pérez-Ruzafa, A., ... Planes, S. (2008). Marine reserves: Size and age do matter. Ecology Letters, 11, 481-489. https://doi.org/ 10.1111/j.1461-0248.2008.01166.x

Convention on Biological Diversity. (1992). Available at: https://www.cbd. int/convention/text/ [Accessed 06 April 2020]

Convention on Biological Diversity. (2010). Strategic plan for biodiversity 2011-2020, including Aichi Biodiversity Targets, Targets 11. Available at: https://www.cbd.int/sp/targets/rationale/target-11/ [Accessed 06 April 2020]

Coppa, S., De Lucia, G. A., Massaro, G., Camedda, A., Marra, S., Magni, P., ... Espinosa, F. (2016). Is the establishment of MPAs enough to preserve endangered intertidal species? The case of Patella ferruginea in the Mal di Ventre Island (W Sardinia, Italy). Aquatic Conservation: Marine and Freshwater Ecosystems, 26, 623-688. https://doi.org/10. 1002/aqc. 2579

Craig, R. K., \& Hughes, T. (2014). Marine protected areas, marine spatial planning, and the resilience of marine ecosystems. Resilience and the Law, 98-141 (2014); FSU College of Law, Public Law Research Paper No. 550. Available at. https://ssrn.com/abstract=1917696 [Accessed 06 April 2020]

De Biasi, A. M., \& Pacciardi, L. (2008). Macrobenthic communities in a fishery exclusion zone and in a trawled area of the middle Adriatic Sea (Italy). Ciencias Marinas, 34, 433-444. https://doi.org/10.7773/cm. v34i4.1382

De Juan, S., Demestre, M., \& Sanchez, P. (2011). Exploring the degree of trawling disturbance by the analysis of benthic communities ranging from a heavily exploited fishing ground to an undisturbed area in the NW Mediterranean. Scientia Marina, 75, 507-516. https://doi.org/10. 3989/scimar.2011.75n3507

Dichmont, C. M., Ellis, N., Bustamante, R. H., Deng, R., Tickell, S., Pascual, R., ... Griffiths, S. (2013). Evaluating marine spatial closures with conflicting fisheries and conservation objectives. Journal of Applied Ecology, 50, 1060-1070. https://doi.org/10.1111/1365-2664.12110

Edgar, G. J., Stuart-Smith, R. D., Willis, T. J., Kininmonth, S., Baker, S. C., Banks, S., ... Thomson, R. J. (2014). Global conservation outcomes depend on marine protected areas with five key features. Nature, 506, 216-220. https://doi.org/10.1038/nature13022

EEC Habitats Directive. (1992). Council Directive 92/43/EEC on the conservation of natural habitats and of wild fauna and flora, 1992. Available at: https://eur-lex.europa.eu/eli/dir/1992/43/2007-01-01 [Accessed 06 April 2020].

Farina, S., Quattrocchi, G., Guala, I., \& Cucco, A. (2018). Hydrodynamic patterns favouring sea urchin recruitment in coastal areas: A Mediterranean study case. Marine Environmental Research, 139, 182-192. https://doi.org/10.1016/j.marenvres.2018.05.013

Frid, C. L. J., Paramor, O. A. L., Brockington, S., \& Bremner, J. (2008). Incorporating ecological functioning into the designation and management of marine protected areas. Hydrobiologia, 606, 69-67. https://doi.org/ 10.1007/s10750-008-9343-y

Galparsoro, I., Borja, A., \& Uyarra, M. C. (2014). Mapping ecosystem services provided by benthic habitats in the European North Atlantic Ocean. Frontiers in Marine Science, 1, 23. https://doi.org/10.3389/ fmars.2014.00023

Gascon, M., Zijlema, W., Vert, C., White, M. P., \& Nieuwenhuijsen, M. J. (2017). Outdoor blue spaces, human health and well-being: A systematic review of quantitative studies. International Journal of Hygiene and Environmental Health, 220, 1207-1221. https://doi.org/10.1016/j. ijheh.2017.08.004

Gill, D. A., Mascia, M. B., Ahmadia, G. N., Glew, L., Lester, S. E., Barnes, M., ... Fox, H. E. (2017). Capacity shortfalls hinder the performance of marine protected areas globally. Nature Communications, 543, 665-669. https://doi.org/10.1038/nature21708

Hatton-Ellis, M., Kay, L., Lewis, M., Lindenbaum, K., Wyn, G., Winterton, A., ... Jones, J. (2012). MPA management report 2:
Assessment of current MPA management in Wales. CCW Marine Science Series, 12/06/03, p. 78, CCW, Bangor

HELCOM. (1994). HELCOM recommendation $15 / 5$ on a system of coastal and marine Baltic Sea protected areas (BSPAs). Available at: https:// www.helcom.fi/action-areas/marine-protected-areas/Background\% 20of\%20HELCOM\%20MPAs/

HELCOM. (2013). HELCOM PROTECT-Overview of the status of the network of Baltic Sea marine protected areas. 31 pp. Available at: https://www.helcom.fi/Lists/Publications/Overview\%20of\%20the\% 20status\%20of\%20the\%20network\%20of\%20Baltic\%20Sea\%20 marine\%20protected\%20areas.pdf. [Accessed 06 April 2020]

Hiddink, J. G., Hutton, T., Jennings, S., \& Kaiser, M. J. (2006). Predicting the effects of area closures and fishing effort restrictions on the production, biomass, and species richness of benthic invertebrate communities. ICES Journal of Marine Science, 63, 822-830. https://doi.org/10. 1016/j.icesjms.2006.02.006

Hooyberg, A., Roose, H., Grellier, J., Elliott, L. R., Lonneville, B., White, M. P., ... Everaert, G. (2020). General health and residential proximity to the coast in Belgium: Results from a cross-sectional health survey. Environmental Research, 184, 109225. https://doi.org/ 10.1016/j.envres.2020.109225

Horta-e-Costa, B., Claudet, J., Franco, G., Erzini, K., Caro, A., \& Gonçalves, E. J. (2016). A regulation-based classification system for Marine Protected Areas (MPAs). Marine Policy, 72, 192-198. https:// doi.org/10.1016/j.marpol.2016.06.021

ICES. (2017). ICES EcoRegions. Available at: http://gis.ices.dk/ geonetwork/srv/eng/catalog.search\#/metadata/4745e824-a6124a1f-bc56-b540772166eb. [Accessed 06 April 2020]

IUCN. (2012). Guidelines for applying the IUCN protected area management categories to marine protected areas. Available at: https:// portals.iucn.org/library/sites/library/files/documents/PAG-019-2nd\% 20ed.-En.pdf. [Accessed 06 April 2020].

IUCN. (2019). IUCN, World Commission on Protected Areas (WCPA) and Assurance Services International (ASI) (2019). In IUCN green list of protected and conserved areas: User manual, version 1.2. Gland, Switzerland: IUCN.

Jessen, S., Morgan, L. E., Bezaury-Creel, J. E., Barron, A., Govender, R., Pike, E. P., ... Moffitt, R. A. (2017). Measuring MPAs in continental North America: How well protected are the ocean estates of Canada, Mexico, and the USA? Frontiers in Marine Science, 4, 279. https://doi. org/10.3389/fmars.2017.00279

Jones, G. P., Srinivasan, M., \& Almany, G. R. (2007). Population connectivity and conservation of marine biodiversity. Oceanography, 20, 100-111. https://www.jstor.org/stable/24860100, https://doi.org/ 10.5670/oceanog.2007.33

Jonsson, P. R., Moksnes, P.-O., Corell, H., Bonsdorff, E., \& Nilsson Jacobi, M. (2020). Ecological coherence of marine protected areas: New tools applied to the Baltic Sea network. Aquatic Conservation: Marine and Freshwater Ecosystems, 30, 743-760. https://doi.org/10. 1002/aqc.3286

Kent, F. E. A., Gray, M. J., Last, K. S., \& Sanderson, W. G. (2016). Horse mussel reef ecosystem services: Evidence for a whelk nursery habitat supporting a shellfishery. International Journal of Biodiversity Science, Ecosystem Services and Management, 12, 2151-3740. https://doi.org/ 10.1080/21513732.2016.1188330

Klein, C. J., Brown, C. J., Halpern, B. S., Segan, D. B., McGowan, J., Beger, M., \& Watson, J. E. M. (2015). Shortfalls in the global protected area network at representing marine biodiversity. Nature Scientific Reports, 5, 17539. https://doi.org/10.1038/srep17539

Laffoley, D., White, A. T., Kilarski, S., Gleason, M., Smith, S., Llewellyn, G., ... Pee, D. (2008). Establishing marine protected area networks-Making it happen (p. 118). Washington, D.C.: IUCN-WCPA, National Oceanic and Atmospheric Administration and the Nature Conservancy. Available from: https://www.iucn.org/content/establishing-resilient-marineprotected-area-networks-making-it-happen [Accessed 06 April 2020] 
Loh, T.-L., Archer, S. K., \& Dunham, A. (2019). Monitoring program design for data-limited marine biogenic habitats: A structured approach. Ecology and Evolution, 9, 7346-7359. https://doi.org/10.1002/ece3.5261

Lutchman, I., Brown, J. \& Kettunen, M. (2008). Review of EU legislation and implementation of marine protected areas (MPAs). In Marine Protected Areas in Europe and the United States. A Report from the Transatlantic Platform for Action on the Global Environment: Institute for European Environmental Policy (Brussels, Belgium) and natural resources defense council (Washington DC, USA). Available at: https://ieep.eu/archive_uploads/411/mpa_tpagefinal1008.pdf. [Accessed 06 April 2020]

MAREANO. (2019). Collecting marine knowledge: The sea in maps and pictures. Available at: http://www.mareano.no/en/. [Accessed 06 April 2020]

Marine Strategy Framework Directive. (2008). Available at: https://eurlex.europa.eu/eli/dir/2008/56/oj [Accessed 06 April 2020].

McConnaughey, R. A., Hiddink, J. G., Jennings, S., Pitcher, R., Kaiser, M., Suuronen, P., ... Hilborn, R. (2020). Choosing best practices for managing impacts of trawl fishing on seabed habitats and biota. Fish and Fisheries, 21, 319-337. https://doi.org/10.1111/faf.1243121.319-337

McDermott, S. F., Buhl-Mortensen, L., Dahle, G., Hart, D., Haynie, A. C., Johannessen, T., ... Stockhausen, W. (2017). Lessons on marine protected area management in northern boreal regions from the United States and Norway. Marine Fisheries Review, 79, 28-79. https://doi. org/10.7755/MFR.79.1.2

Mills, M., Jupiter, S. D., Pressey, R. L., Ban, N. C., \& Comley, J. (2011). Incorporating effectiveness of community-based management in a national marine gap analysis for Fiji. Conservation Biology, 25, 1155-1164. https://doi.org/10.1111/j.1523-1739.2011.01749.x

MPAtlas. (2020). Atlas of marine protection. Available at: http://www. mpatlas.org/map/mpas/. [Accessed 06 April 2020].

O'Leary, B. C., Winther-Janson, M., Bainbridge, J. M., Aitken, J., Hawkins, J. P., \& Roberts, C. M. (2016). Effective coverage targets for ocean protection. Conservation Letters, 9, 398-404. https://doi.org/ 10.1111/conl.12247

Olive, P. J. W. (1993). Management of the exploitation of the lugworm Arenicola marina and the ragworm Nereis virens (Polychaeta) in conservation areas. Aquatic Conservation: Marine and Freshwater Ecosystems, 3, 1-24. https://doi.org/10.1002/aqc.3270030102

OSPAR. (2003). OSPAR recommendation $2003 / 3$ on a network of marine protected areas. Available at: https://www.ospar.org/work-areas/bdc/ marine-protected-areas [Accessed 06 April 2020]

OSPAR. (2007). Convention for the protection of the marine environment of the North-East Atlantic (2007). Guidance to assess the effectiveness of management of OSPAR MPAs: A self-assessment scorecard. Reference Number: 2007-2005. Available at: https://www.ospar.org/workareas/bdc/marine-protected-areas/guidance-for-the-developmentand-management-of-the-ospar-network [Accessed 06 April 2020]

OSPAR. (2008). 2007 Progress report on the OSPAR network of marine protected Areas. Publication Number 359/2008. Available at: https:// www.ospar.org/documents?v=7093 [Accessed 06 April 2020]

OSPAR. (2016). 2016 Status report on the OSPAR network of marine protected areas. Biodiversity Series. Publication Number 693/2017. Available at: https://oap.ospar.org/en/ospar-assessments/ intermediate-assessment-2017/biodiversity-status/marine-protectedareas/ [Accessed 06 April 2020]

Palumbi, S. R. (2003). Population genetics, demographic connectivity and the design of marine protected areas. Ecological Applications, 13 146-158. https://doi.org/10.1890/1051-0761(2003)013[0146: pgdcat]2.0.co;2

Planes, S., Galzin, R., Garcia-Rubies, A., Goni, R., Harmelin, J. G., LeDireach, L., ... Quetglas, A. (2000). Effects of marine protected areas on recruitment processes with special reference to Mediterranean littoral ecosystems. Environmental Conservation, 27, 126-143. https:// doi.org/10.1017/S0376892900000175
Pomeroy, R. S., Parks, J. E., \& Watson, L. M. (2004). How is your MPA doing? A guidebook of natural and social indicators for evaluating marine protected area management effectiveness. Gland, Switzerland and Cambridge, UK: IUCN.

PRIMER-e. (2006). Plymouth routines in multivariate ecological research v6. Plymouth, United Kingdom: PRIMER-E Ltd, Plymouth Marine Laboratory.

R Core Team. (2013). R: A language and environment for statistical computing. Vienna, Austria: R Foundation for Statistical Computing. Available at: http://www.R-project.org/ [Accessed 06 April 2020]

Renaud, P. E., Morata, N., Ambrose, W. G. Jr., Bowie, J. J., \& Chiuchiolo, A. (2007). Carbon cycling by seafloor communities on the eastern Beaufort Sea shelf. Journal of Experimental Marine Biology and Ecology, 349, 248-260. https://doi.org/10.1016/j.jembe.2007.05.021

Reynolds, P. C., \& Braithwaite, D. (2010). Towards a conceptual framework for wildlife tourism. Tourism Management, 22, 31-42. https://doi.org/ 10.1016/S0261-5177(00)00018-2

Roberts, C. M., O'Leary, B. C., McCauley, D. J., Cury, P. M., Duarte, C. M., Lubchenco, J., ... Worm, B. (2017). Marine reserves can mitigate and promote adaptation to climate change. Proceedings of the National Academy of Sciences of the United States of America, 114, 6167-6175. https://doi.org/10.1073/pnas.1701262114

Rodríguez-Rodríguez, D., Sciberras, M., Foster, N. L., \& Attrill, M. J. (2015). Status of management effort in 153 marine protected areas across the English Channel. Marine Pollution Bulletin, 94, 168-175. https://doi. org/10.1016/j.marpolbul.2015.02.036

Ruiz-Frau, A., Possingham, H. P., Edwards-Jones, G., Klein, C. J., Segan, D., \& Kaiser, M. J. (2015). A multidisciplinary approach in the design of marine protected areas: Integration of science and stakeholder-based methods. Ocean and Coastal Management, 103, 86-93. https://doi.org/10.1016/j.ocecoaman.2014.11.012

Shakeel, E., Arora, D., Jamal, Q. M. S., Akhtar, S., Khan, M. K. A., Kamal, M. A., ... Arif, J. M. (2018). Marine drugs: A hidden wealth and a new epoch for cancer management. Current Drug Metabolism, 19, 523-543. https://doi.org/10.2174/13892002186661702211 05402

Shanks, A. L. (2009). Pelagic larval duration and dispersal distance revisited. Biological Bulletin, 216, 373-385. https://doi.org/10.1086/ BBLV216n3p373

Snelgrove, P. V. R., Soetaert, K., Solan, M., Thrush, S., Wei, C.-L., Danovaro, R., ... Volkenborn, N. (2018). Global carbon cycling on a heterogeneous seafloor. Trends in Ecology \& Evolution, 33, 96-105. https://doi.org/10.1016/j.tree.2017.11.004

Solandt, J.-L. (2018). A stocktake of England's MPA network-Taking a global perspective approach. Biodiversity, 19, 34-41. https://doi.org/ 10.1080/14888386.2018.1464950

Staub, F. \& Hatziolos, M. E. (2004). Score card to assess progress in achieving management effectiveness goals for marine protected areas: The World Bank. Available at: http://documents.worldbank.org/curated/en/ 101301468135588216/pdf/ 32938a10ScoreC1rogress200401public1.pdf

Stelzenmüller, V., Breen, P., Stamford, T., Thomsen, F., Badalamenti, F., Borja, Á., ... ter Hofstede, R. (2013). Monitoring and evaluation of spatially managed areas: A generic framework for implementation of ecosystem based marine management and its application. Marine Policy, 37, 149-164. https://doi.org/10.1016/j.marpol.2012.04.012

Stelzenmüller, V., Vega Fernández, T., Cronin, K., Röckmann, C., Pantazi, M., Vanaverbeke, J., ... van Hoof, L. (2015). Assessing uncertainty associated with the monitoring and evaluation of spatially managed areas. Marine Policy, 51, 151-162. https://doi.org/10.1016/j. marpol.2014.08.001

Stevens, T. F., Sheehan, E. V., Gall, S. C., Fowell, S. C., \& Attrill, M. J. (2014). Monitoring benthic biodiversity restoration in Lyme Bay marine protected area: Design, sampling and analysis. Marine Policy, 45, 310-317. https://doi.org/10.1016/j.marpol.2013.09.006 
Stolton, S., \& Dudley, N. (2016). METT handbook: A guide to using the Management Effectiveness Tracking Tool (METT). WWF-UK. Woking. Available at: https://assets.panda.org/downloads/mett2_final_version_july_ 2007.pdf. [Accessed 06 April 2020]

UNEP. (2006). Marine and coastal ecosystems and human wellbeing: A synthesis report based on the findings of the Millennium Ecosystem Assessment: UNEP, 76. Available at: https://www.millenniumassessment. org/documents/Document.799.aspx.pdf. [Accessed 06 April 2020].

UNEP-WCMC \& IUCN. (2019). Protected planet: The world database on protected areas (WDPA). Cambridge, UK: UNEP-WCMC \& IUCN. Available at: www.protectedplanet.net. [Accessed 06 April 2020]

Van Hoey, G., Borja, A., Birchenough, S., Buhl-Mortensen, L., Degraer, S., Fleisher, D., ... Schröder, A. (2010). The use of benthic indicators in Europe: From the Water Framework Directive to the Marine Strategy Framework Directive. Marine Pollution Bulletin, 60, 2187-2219. https://doi.org/10.1016/j.marpolbul.2010.09.015

Van Hoey, G., Wischnewski, J., Craeymeersch, J., Dannheim, J., Enserink, L., Guerin, L., ... Berghe, M. V. (2019). Methodological elements for optimising the spatial monitoring design to support regional benthic ecosystem assessments. Environmental Monitoring and Assessment, 191, 423. https://doi.org/10.1007/s10661-019-7550-9

Vandeperre, F., Higgins, R. M., Sánchez-Meca, J., Maynou, F., Goñi, R., Martín-Sosa, P., ... Santos, R. S. (2011). Effects of no-take area size and age of marine protected areas on fishery yields: A meta-analytical approach. Fish and Fisheries, 12, 412-426. https://doi.org/10.1111/j. 1467-2979.2010.00401.x
Wells, S., Ray, G. C., Gjerde, K. M., White, A. T., Muthiga, N., Bezaury Creel, J. E., ... Reti, J. (2016). Building the future of MPAs-Lessons from history. Aquatic Conservation: Marine and Freshwater Ecosystems, 26, 101-125. https://doi.org/10.1002/aqc.2680

Wilson, M. A., Costanza, R., Boumans, R., \& Liu, S. (2005). Integrated assessment and valuation of ecosystem goods and services provided by coastal systems. In J. G. Wilson (Ed.), The intertidal ecosystem: The value of Ireland's shores (pp. 1-24). Available at: https://pdfs. semanticscholar.org/843d/27f4a28a64ed6d10750ebbcbd2199be7c9 c4.pdf\#page=17 [Accessed 06 April 2020]

\section{SUPPORTING INFORMATION}

Additional supporting information may be found online in the Supporting Information section at the end of this article.

How to cite this article: Greathead C, Magni P,

Vanaverbeke J, et al. A generic framework to assess the representation and protection of benthic ecosystems in European marine protected areas. Aquatic Conserv: Mar Freshw Ecosyst. 2020;30:1253-1275. https://doi.org/10.1002/aqc. $\underline{3401}$ 